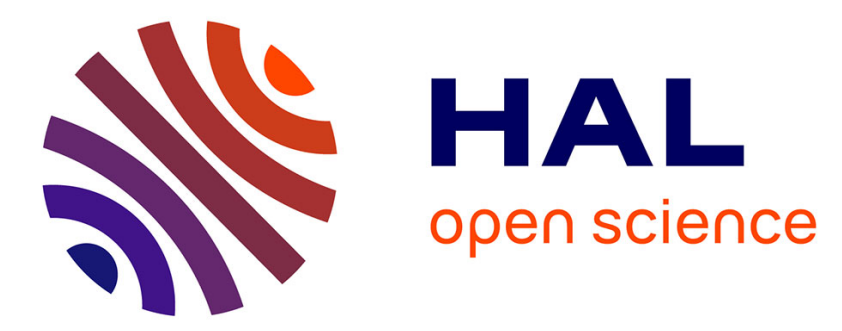

\title{
Immobilization of metal hexacyanoferrates in chitin beads for cesium sorption: synthesis and characterization
}

Vincent Thierry, Vincent C., Barre Yves, Yannick Guari, Saout G. Le, Guibal Eric

\section{- To cite this version:}

Vincent Thierry, Vincent C., Barre Yves, Yannick Guari, Saout G. Le, et al.. Immobilization of metal hexacyanoferrates in chitin beads for cesium sorption: synthesis and characterization. Journal of Materials Chemistry A, 2015, pp.10007-10021. 10.1039/c4ta01128g . hal-01009354

\section{HAL Id: hal-01009354 https://hal.science/hal-01009354}

Submitted on 7 Jun 2021

HAL is a multi-disciplinary open access archive for the deposit and dissemination of scientific research documents, whether they are published or not. The documents may come from teaching and research institutions in France or abroad, or from public or private research centers.
L'archive ouverte pluridisciplinaire HAL, est destinée au dépôt et à la diffusion de documents scientifiques de niveau recherche, publiés ou non, émanant des établissements d'enseignement et de recherche français ou étrangers, des laboratoires publics ou privés. 


\title{
Immobilization of metal hexacyanoferrates in chitin beads for cesium sorption: synthesis and characterization
}

\author{
T. Vincent, ${ }^{a}$ C. Vincent, ${ }^{b}$ Y. Barré, ${ }^{b}$ Y. Guari, ${ }^{c}$ G. Le Saout ${ }^{d}$ and E. Guibal ${ }^{\star a}$
}

Five metal-potassium hexacyanoferrate/chitin composites (based on $\mathrm{Cu}, \mathrm{Ni}, \mathrm{Zn}$, Co or Fe co-metal) have been prepared and characterized, using SEM-EDX, TEM, X-ray diffraction and FT-IR, before being compared for $\mathrm{Cs}(\mathrm{I})$ and ${ }^{137} \mathrm{Cs}(\mathrm{I})$ sorption. The $\mathrm{Zn}$-ion exchanger was characterized by a much larger crystal size of about $250 \mathrm{~nm}$ compared with a few tens of $\mathrm{nm}$ for other ion-exchangers. The ionexchangers are well distributed in the whole mass of the composite and they are fully accessible to Cs(I), as evidenced by $\mathrm{Cs}(\mathrm{l})$ distribution after metal sorption. Uptake kinetics can be modeled using both the pseudo-second order rate equation and the Crank equation (resistance to intraparticle diffusion coefficient). Sorption isotherms showed substantial differences in the sorbents that can be ranked as $\mathrm{Cu}$ $>\mathrm{Ni}>\mathrm{Zn}>\mathrm{Co}>\mathrm{Fe}$. However, based on ${ }^{137} \mathrm{Cs} K_{\mathrm{d}}$ values, the sorbents can be ranked as $\mathrm{Co} \gg \mathrm{Fe} \gg \mathrm{Cu}$ $\gg \mathrm{Ni}>\mathrm{Zn}$. Taking into account the cost and toxicity of metals (both in terms of manufacturing and potential metal release) a Prussian Blue based sorbent (i.e., iron-potassium hexacyanoferrate/chitin composite) sounds to be a good composite for $\mathrm{Cs}($ I) recovery from radionuclide-containing effluents.

\section{Introduction}

Apart from nuclear accidents (Fukushima, Three Miles Island, Chernobyl), the nuclear power industry generates, under normal operational conditions, effluents that contain radionuclides and that require extensive treatment and confinement. These effluents may contain a great diversity of radionuclides but also base metals, alkaline and alkaline earth metals, in concentrations several orders of magnitude greater than the levels reached by radionuclides. It is thus necessary to develop very selective extraction processes for removing these trace radionuclides in complex solutions. Though chelating or ionexchange resins can be used, they are generally not selective enough for making the process competitive and extendable to a large scale. More competitive processes have been developed using inorganic ion exchangers. ${ }^{1,2}$ Their main interest consists in the selectivity brought by the crystallographic arrangement of the inorganic material (cage size and arrangement) and by the

${ }^{a}$ Ecole des mines d'Alès, Centre des Matériaux des Mines d'Alès, C2MA-MPA-BCI, 6 avenue de Clavières, F-30319 AlèsCedex, France. E-mail: eric.guibal@mines-ales.fr ${ }^{b}$ Commissariat à l'Energie Atomique, CEA Marcoule, DEN/DTCD/SPDE/LPSD, BP 17171, F-30207 Bagnols sur Cèze, France

'Institut Charles Gerhardt - UMR5253, CNRS-UM2-ENSCM-UM1, CMOS, Université Montpellier II, Place Eugène Bataillon - Case 1701, F-34095 Montpellier Cedex 05, France

${ }^{d}$ Ecole des mines d'Alès, Centre des Matériaux des Mines d'Alès, C2MA-MSGC-MHB, 6 avenue de Clavières, F-30319 Alès Cedex, France compatibility in the size and charge of exchangeable cations with target radionuclides. These ion-exchangers successfully recover $\mathrm{Cs}(\mathrm{I})$ or $\mathrm{Rb}(\mathrm{I})$, with the hydrated radius close to $3.29 \AA$, even in the presence of a large excess of alkaline metals $\mathrm{K}(\mathrm{I})$, $\mathrm{Na}(\mathrm{I})$, for example, having a hydrated radius of $3.31 \AA$ and 3.58 $\AA$, respectively. ${ }^{3}$ The type of metal associated with the potassium hexacyanoferrate moiety and the experimental conditions for the synthesis of the metal hexacyanoferrate (drop by drop addition of precursors, proportions of precursors, temperature, and aging) influence the structure of the final product, the size of insoluble compounds, its exchangeability properties, and finally its affinity for radionuclides. The main drawback of these materials is generally related to their small size that makes their recovery at the end of the sorption process a critical step, which requires extensive solid/liquid separation, ${ }^{4}$ to prevent possible loss of hazardous materials such as radionuclide-loaded ionexchangers etc. In addition, these nano- or micro-particles cannot be directly used in fixed-bed columns due to pressure loss and clogging; this prevents the process from being readily transferable at a large-scale. Alternatively, granulation of the material for use in a fixed-bed column generally leads to decrease in sorption properties due to loss in accessibility and availability of reactive groups. ${ }^{5}$ All these reasons may explain why numerous studies have been dedicated in the last few decades to the immobilization of nano- or micro-particles of metal hexacyanoferrates in porous materials or at the surface of structured materials. $^{6,7}$

Several techniques of immobilization of metal hexacyanoferrate complexes on mineral or organic supports have 
been described using (a) encapsulation, ${ }^{\mathbf{8 - 1 0}}$ (b) impregnation or deposition, ${ }^{\mathbf{1 1}, \mathbf{1 2}}$ or (c) in situ synthesis of metal hexacyanoferrate complexes. ${ }^{13,14}$ In the present study, the encapsulation process was preferred using biopolymers for the immobilization of presynthesized metal hexacyanoferrate micro-particles. The size and charge properties of the produced metal hexacyanoferrates, from co-metal salt and potassium hexacyanoferrate precursors, make their recovery difficult by solid/liquid separation; it was necessary to use a specific conditioning of these products, by biopolymer stabilization, before they can be readily recovered and immobilized in a biopolymer matrix. Different biopolymers have been previously tested for the encapsulation of ionexchangers, such as alginate, ${ }^{15-18}$ or chitosan. ${ }^{19}$ Most of these materials have been designed in the form of composite spherical resins but the concept can be extended to elaborate highly macroporous composite foams or sponges. ${ }^{20}$ Chitosan, an aminopolysaccharide produced at the industrial scale from crustacean shells, was selected, in the present study, for the incorporation of metal hexacyanoferrate complexes in the form of spherical beads. Since chitosan is soluble in most acid solutions (with the exception of sulfuric acid solutions), a reacetylation post-treatment was carried out for improving the chemical stability of composite materials.

There are several metal hexacyanoferrates that can be used for the sorption of radionuclides, more specifically cesium. The most frequently used are Prussian Blue (iron potassium hexacyanoferrate), ${ }^{13,18,21}$ nickel-potassium hexacyanoferrate, ${ }^{11,22,23}$ and copper-potassium hexacyanoferrate. ${ }^{12,24}$ However, some other co-cations have also been cited such as cobalt potassium hexacyanoferrate ${ }^{25,26}$ and zinc potassium hexacyanoferrate. ${ }^{27,28}$

The objectives of this work are to (a) synthesize a series of metal-hexacyanoferrate/chitin composites for the sorption of cesium, (b) characterize these materials, using FT-IR spectroscopy, X-ray diffraction spectroscopy, SEM-EDX and TEM analysis, and (c) compare the Cs(I) sorption properties of the different materials in synthetic solutions. A final test was performed on ${ }^{137} \mathrm{Cs}$ solutions.

\section{Materials and methods}

\section{Materials}

Potassium hexacyanoferrate $\left(\mathrm{K}_{4}\left[\mathrm{Fe}(\mathrm{CN})_{6}\right] \cdot 3 \mathrm{H}_{2} \mathrm{O}\right.$, Riedel-de Haën), nickel sulfate $\left(\mathrm{NiSO}_{4} \cdot 6 \mathrm{H}_{2} \mathrm{O}\right.$, Chem-Lab), zinc sulfate $\left(\mathrm{ZnSO}_{4} \cdot 7 \mathrm{H}_{2} \mathrm{O}\right.$, Chem-Lab), copper sulfate $\left(\mathrm{CuSO}_{4} \cdot 5 \mathrm{H}_{2} \mathrm{O}\right.$, Chem$\mathrm{Lab})$, cobalt sulfate $\left(\mathrm{CoSO}_{4} \cdot 7 \mathrm{H}_{2} \mathrm{O}\right.$, Chem-Lab), iron chloride $\left(\mathrm{FeCl}_{3} \cdot 3 \mathrm{H}_{2} \mathrm{O}\right.$, Chem-Lab), and acetic anhydride $\left(\mathrm{C}_{4} \mathrm{H}_{6} \mathrm{O}_{3}\right.$, SigmaAldrich) were supplied as reagent grade products. Acetic acid (80\% w/w, Carlo Erba) and ethanol (96\% w/w, Sodipro) were technical products. Chitosan (molecular weight $125000 \mathrm{~g}$ $\mathrm{mol}^{-1}$, deacetylation degree: $87 \%$ ) was supplied by Aber-Technologies (France). Cesium nitrate was purchased from Merck AG (Germany).

\section{Synthesis}

The synthesis of the metal hexacyanoferrate complexes consisted in mixing two precursors for $30 \mathrm{~min}$ under strong agitation: (i) potassium hexacyanoferrate $(100 \mathrm{~mL}, 3.62 \mathrm{~g})$, and (ii) metal sulfate (except for the iron complex, where iron(III) chloride was used) $(100 \mathrm{~mL})$. The molar ratio between the metal precursor and potassium hexacyanoferrate was systematically set at 1.2 : 1 (Fe: 2.23 g; Ni: 2.70 g; Zn: 2.96 g; Co: 2.89 g; Cu: 2.57 g). For iron-hexaCNFe, the hexacyanoferrate solution was injected into the metal precursor solution drop-by-drop while for the other complexes the two solutions were mixed in a single step. At the end of this first step, $1 \mathrm{~L}$ of demineralized water was added to the suspension.

This suspension was then added to $2 \mathrm{~L}$ of chitosan solution (at $0.05 \%, \mathrm{w} / \mathrm{w}$ ) to stabilize the complexes (charge neutralization, partial or complete) which improves the decantation of the material that can be readily recovered by filtration on a paper membrane. This wet material (CSC) was thus mixed with 100 $\mathrm{mL}$ of water and $100 \mathrm{~mL}$ of a $4 \% \mathrm{w} / \mathrm{w}$ chitosan solution in two steps: softly, and then under UltraTurax (for $5 \mathrm{~min}$ ).

Shaping of the material was performed by pumping the viscous chitosan/stabilized complex suspension through a thin nozzle (changing the diameter of the nozzle for producing different sizes of beads) into a liquid $\mathrm{N}_{2}$ bath. Frozen beads were finally freeze-dried.

The final step consisted in the re-acetylation of chitosan. ${ }^{29}$ One gram of the metal-hexaCNFe/chitosan composite was mixed with $40 \mathrm{~mL}$ of ethanol and $10 \mathrm{~mL}$ of acetic anhydride under reflux for $1 \mathrm{~h}$. The products were then rinsed once with ethanol to remove the unreacted reagent and finally three times with demineralized water. The metal-hexaCNFe/chitin composites were then freeze-dried (see the ESI, $\uparrow$ Fig. AM1, for macroscopic optical observation).

\section{Characterization}

SEM and SEM-EDX analysis. The morphology and the distribution of the inorganic ion-exchanger (and Cs, when relevant) in the materials were determined with Scanning Electron Microscopy coupled with Energy Dispersive X-ray analysis (SEM-EDX). SEM observations were performed using an Environmental Scanning Electron Microscope (ESEM) Quanta FEG 200, equipped with an OXFORD Inca 350 Energy Dispersive X-ray microanalysis (EDX) system. The use of environmental SEM allowed the direct observations of materials, without previous metallization of the samples. The topography of the samples was observed using secondary electron flux while the backscattered electrons were used for the identification and localization of heavy metals at the surface of the materials (by phase contrast). SEM-EDX facilities were used for the detection of elements and their semiquantitative analysis (Cs and principal elements representative of the inorganic ion-exchanger; i.e., $\mathrm{Fe}, \mathrm{K}$ and $\mathrm{Ni}$ ). The standard accelerating voltage was set at $15.0 \mathrm{keV}$. The samples were analyzed on freshly cut sections (mechanical shock after liquid nitrogen icing).

TEM analysis. Samples for Transmission Electron Microscopy (TEM) measurements were prepared by depositing one drop of the solution on copper grids. TEM measurements were carried out at $100 \mathrm{kV}$ with a JEOL 1200 EXII microscope. 
XRD analysis. X-ray diffraction (XRD) data (on powders) were collected using a BRUKER Advance D8 diffractometer in a $\theta-\theta$ configuration employing $\mathrm{Cu} \mathrm{K}_{\alpha}$ radiation $(\lambda=1.54 \AA)$ with a fixed divergence slit size of $0.3^{\circ}$ and a rotating sample stage. The samples were scanned between $10^{\circ}$ and $70^{\circ}$ with a VANTEC- 1 detector. The qualitative analysis was performed with the X'Pert High Score Plus software (version 2.1).

Material mineralization. Wet mineralization of the materials was performed by reaction with an $18 \mathrm{M}$ sulfuric acid solution at boiling temperature followed by successive additions of $1 \mathrm{~mL}$ volumes of hydrogen peroxide $(30 \% \mathrm{v} / \mathrm{v})$, till complete discoloration. The solutions were then analyzed for $\mathrm{Fe}, \mathrm{Ni}$ and $\mathrm{K}$ using an ICP-AES Activa M (Jobin-Yvon, inductively coupled plasma atomic emission spectrometer).

Size analysis and surface charge analysis. The size of metalhexacyanoferrate complex particles was determined using a laser diffraction particle size analyzer LS 13320 MW Beckman Coulter on bulk particles (that were not stabilized by chitosan). The zeta potentials of the particles both in the bulk state and those stabilized by chitosan were determined using a Nano ZS Zetasizer (Malvern).

FT-IR spectrometry. Fourier-transform infra-red spectrometry measurements were performed on metal-hexaCNF/chitin composites using a Nicolet 380 FT-IR spectrometer (equipped with the OMNIC Lite software, 32 scans and a $2 \mathrm{~cm}^{-1}$ resolution). Samples were directly deposited on the Smart Orbit ATR (attenuated total reflectance) accessory (equipped with a diamond crystal).

Thermogravimetric analysis. Thermal degradation of the iron-potassium hexacyanoferrate/chitin composite was investigated using a simultaneous DSC-TGA analyzer (SDT2960, TA Instruments), equipped with the Thermal Advantage software. The thermal ramp followed the sequence: (a) $3{ }^{\circ} \mathrm{C} \min ^{-1}$ up to $100{ }^{\circ} \mathrm{C}$, followed by an isotherm step for $30 \mathrm{~min}$, (b) $3{ }^{\circ} \mathrm{C} \mathrm{min}{ }^{-1}$ up to $250^{\circ} \mathrm{C}$, followed by an isotherm step for $30 \mathrm{~min}$, and (c) $3{ }^{\circ} \mathrm{C} \min ^{-1}$ up to $900{ }^{\circ} \mathrm{C}$, followed by an isotherm step for $150 \mathrm{~min}$.

Metal sorption. All cesium solutions were prepared from a stock solution $\left(1 \mathrm{~g} \mathrm{Cs} \mathrm{L}^{-1}\right)$ by dilution with a $0.01 \mathrm{M}$ sodium nitrate solution (as the background salt). The initial (pH 5-6) and the final $\mathrm{pH}$ were systematically monitored but the $\mathrm{pH}$ was not adjusted during the sorption. All sorbent particles (stored as freeze-dried materials) were moistened before being used by shaking in demineralized water for 24 hours (superficial and extra-particle water was removed before the particles could be introduced in metal solutions). Experiments were performed at room temperature (i.e., $20.0 \pm 1.5^{\circ} \mathrm{C}$ ).

Uptake kinetics. Uptake kinetics were determined by contact (under stirring agitation) of $1 \mathrm{~L}$ of cesium solution (initial concentration, $C_{0}: 10 \mathrm{mg} \mathrm{Cs} \mathrm{L}^{-1}$ ) with $0.1 \mathrm{~g}$ (m, dry weight, d.w.) of the metal-potassium hexacyanoferrate/chitin composite for 48 hours. Samples were collected, filtered (membrane pore size $\approx 1 \mu \mathrm{m}$ ) and analyzed by atomic absorption spectrometry (AAS, Varian AA20 spectrometer; wavelength, $\lambda: 852.1 \mathrm{~nm}$ ). Similar experiments were performed with bulk and chitosan-stabilized metal-potassium hexacyanoferrate complexes.
Sorption isotherms. Sorption isotherms were obtained by contact, on a reciprocal shaker, of $0.1 \mathrm{~g}$ of the metal-potassium hexacyanoferrate/chitin composite with $50 \mathrm{~mL}$ of cesium solution $(V, \mathrm{~L})$. The initial concentration, $C_{0}$, varied between 5 and

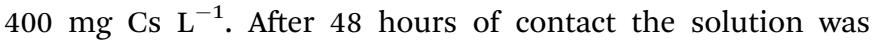
filtered and the residual concentrations $\left(C_{\mathrm{eq}}, \mathrm{mg} \mathrm{Cs} \mathrm{L}^{-1}\right)$ were analyzed by AAS. The sorption capacity $\left(q, \mathrm{mg} \mathrm{Cs} \mathrm{g}^{-1}\right)$ was calculated by the mass balance equation: $q=V\left(C_{0}-C_{\mathrm{eq}}\right) / m$.

${ }^{137} \mathrm{Cs}$ preliminary sorption tests. For testing ${ }^{137} \mathrm{Cs}$ sorption the same procedure as for sorption isotherms was adopted (with $V: 0.05 \mathrm{~L} ; m: 0.05 \mathrm{~g}$ (d.w.); here the contact time was set to 24 hours). The activity of the initial solution $\left(A_{0}, \mathrm{~Bq} \mathrm{~L}^{-1}\right)$ was measured at $37000 \mathrm{~Bq} \mathrm{~L}^{-1}$ by gamma counting (using a Eurisys Mesures counter equipped with a germanium detector). The residual activity $\left(A_{\mathrm{f}}, \mathrm{Bq} \mathrm{L}{ }^{-1}\right)$ was measured and used to calculate the decontamination factor (DF: $A_{0} / A_{\mathrm{f}}$ ) and the distribution coefficient $\left(K_{\mathrm{d}}, \mathrm{L} \mathrm{g}^{-1}\right.$ : $\left.\mathrm{Cs}_{\text {sorbent }} / \mathrm{Cs}_{\text {solution }}=\left(A_{0}-A_{\mathrm{f}}\right) V /\left(m A_{\mathrm{f}}\right)\right)$.

\section{Results and discussion}

\section{Synthesis}

The elaboration of composite materials followed basically four main phases (see Scheme 1 in the ESI: $\dagger$ (a) synthesis of the metal hexacyanoferrate complex (bulk complex), (b) stabilization of the complex with chitosan (CSC), (c) manufacturing of metal hexacyanoferrate/chitosan beads (shaping step), and (d) reacetylation of chitosan to prepare metal hexacyanoferrate/ chitin composites (metal-hexaCNFe/chitin). The structure of the final material appears in Scheme 2 (ESI $\dagger$ ).

Though the experimental conditions may influence the properties of the synthesized metal-potassium hexacyanoferrates (especially the molar ratio between the two precursors), in this screening work, the molar ratio was kept constant (metal salt/potassium hexacyanoferrate molar ratio was set to $1.2: 1$ ). The surface analysis of bulk particles showed negative values (zeta potential analysis) from $-17 \mathrm{mV}$ down to $-51 \mathrm{mV}$ (depending on the metal co-cation) (see the ESI, $\uparrow$ Table AM1). These surface charges may contribute to stabilize the bulk particles in suspension in the solution. However, this was not sufficient to prevent their agglomeration (through weak forces, quite easy to destabilize) as shown by the size analysis (Zetasizer analysis, see the ESI, $\uparrow$ Table AM2, Fig. AM2): the particle sizes were significantly larger than the sizes measured by TEM after dispersion (see below). After addition of chitosan (for the preparation of CSC, chitosan stabilized complexes), in most cases (with the remarkable exception of Prussian Blue, iron-potassium hexacyanoferrate complex), the negative value of the zeta potential tended to decrease (in absolute value). In the case of $\mathrm{Ni}$-hexaCFe and Co-hexaCFe, the surface charge tended to $0 \mathrm{mV}$. Under selected experimental conditions, the materials tended to settle quite readily, independent of the final surface charge: this means that chitosan contributes to facilitate the recovery of Prussian Blue analogues not only by charge neutralization (coagulation effect) but also through its flocculating effect (in relation with the high molecular weight of the biopolymer). An in-depth study of the surface charge by changing the proportion of chitosan (as the complex stabilizer) 
would be probably necessary for optimizing this part of the synthesis procedure.

The encapsulated materials were roughly spherical (see the ESI, $\uparrow$ Fig. AM1); the size of the beads was around $3.5 \mathrm{~mm}(L$ beads), though small beads ( $S: 2 \mathrm{~mm}$ in diameter) were also produced by changing the size of the extrusion nozzle and using an air flow pulsed through a concentric nozzle.

\section{Sorbent characterization - physical properties}

Fig. 1 shows the shape and size of the different bulk materials. Significant changes can be observed: large, relatively homogeneous in size (average value close to $250 \mathrm{~nm}$ ) and well-defined crystals of hexaCNFe-Zn were obtained, while for other compounds the crystals were smoothened or melted and much smaller in size (few nanometers to a few tens of nanometers). This is contradictory to the values obtained by laser light scattering analysis (using the Zetasizer, see the ESI, $\uparrow$ Table AM2 and Fig. AM2). This can be probably attributed to the tendency of particles to agglomerate while analyzing with the Zetasizer, or to the fact that this equipment can only detect and analyze the largest particles. The two analyses only converged in the case of zinc-potassium hexacyanoferrate complex (around $250 \mathrm{~nm}$ in diameter). These sizes of particles are larger than those obtained by the in situ synthesis of Prussian Blue in an alginate matrix (i.e., centered around $4-5 \mathrm{~nm}),{ }^{\mathbf{1 4}}$ or chitosan matrix (i.e., centered around $3-4 \mathrm{~nm}),{ }^{19}$ or immobilized in mesoporous supports (around $6 \mathrm{~nm}$ ). ${ }^{13}$ The shape and size for metal-potassium hexacyanoferrate complexes other than $\mathrm{Zn}$ are very similar to those obtained for Prussian Blue deposed on magnetic nanoparticles. ${ }^{30}$ The cubic shape obtained with the zinc complex was also reported in the case of the Prussian Blue complex (with a size close to $110 \mathrm{~nm}){ }^{24}$

SEM photographs of the cross-sections of metal-potassium hexacyanoferrate/chitin capsules are reported in Fig. 2. These pictures confirm the quasi-spherical shape of the beads and the order of magnitude in size of encapsulated materials. The inner macroporosity can be clearly identified by the presence of sheets and a flaky structure. This is the result of the synthesis procedure, which includes the fast congelation in liquid nitrogen and the freeze-drying of the material (ice sublimation contributes to the appearance of the flaky structure).

Fig. 3 and 4 report the SEM-EDX analysis of a cross-section of the copper-potassium hexacyanoferrate/chitin composite before and after Cs(I) sorption. Similar analyses were performed on the other composite materials. The figures show the SEM photographs with the EDX analysis (for identifying the main elements in the particles) and the map distribution of elements in the cross-section: $O$ as the tracer of the encapsulating material, $\mathrm{K}, \mathrm{Fe}$ and $\mathrm{Cu}$ as the tracers of the ion-exchanger, and Cs for characterization of metal sorption. The distribution of elements is homogeneous both for the elements representative of the ion-exchanger and Cs. This means that the ion-exchanger was homogeneously distributed in the whole mass of the beads and that all reactive groups remain accessible and available for Cs sorption. Though most of Cs(I) ion exchange takes place with $\mathrm{K}(\mathrm{I}), \mathrm{Cs}(\mathrm{I})$ can also bind into the vacancies of the ion-exchanger structure or be exchanged with the other co-metal associated with the hexacyanoferrate moiety. The SEM-EDX observation confirms that $\mathrm{Cs}(\mathrm{I})$ is homogeneously distributed and that all reactive sites remain available. The macroporous structure may explain that at the saturation of the sorbent it is not possible to see a gradient in the distribution of Cs. The decrease in the intensity of $\mathrm{K}$ in the X-ray diffraction analysis confirms that $\mathrm{Cs}(\mathrm{I})$ has been exchanged with K(I). Actually, for some ion-exchangers (including $\mathrm{Cu}$-hexaCNFe and $\mathrm{Zn}$-hexaCNFe), the peak for $\mathrm{K}$ almost disappeared after Cs(I) binding on the X-ray spectra.

Fig. AM3 (see the ESI $\dagger$ ) compares the EDX analysis for the zinc-potassium hexacyanoferrate/chitin composite before and after Cs(I) sorption. The analyses were performed on localized places (identified by "Spectre" on the SEM photographs). This may explain the difference in the intensity of the signals for elements associated with the ion-exchanger (analysis focused on the ion-exchanger or on a broader area where the

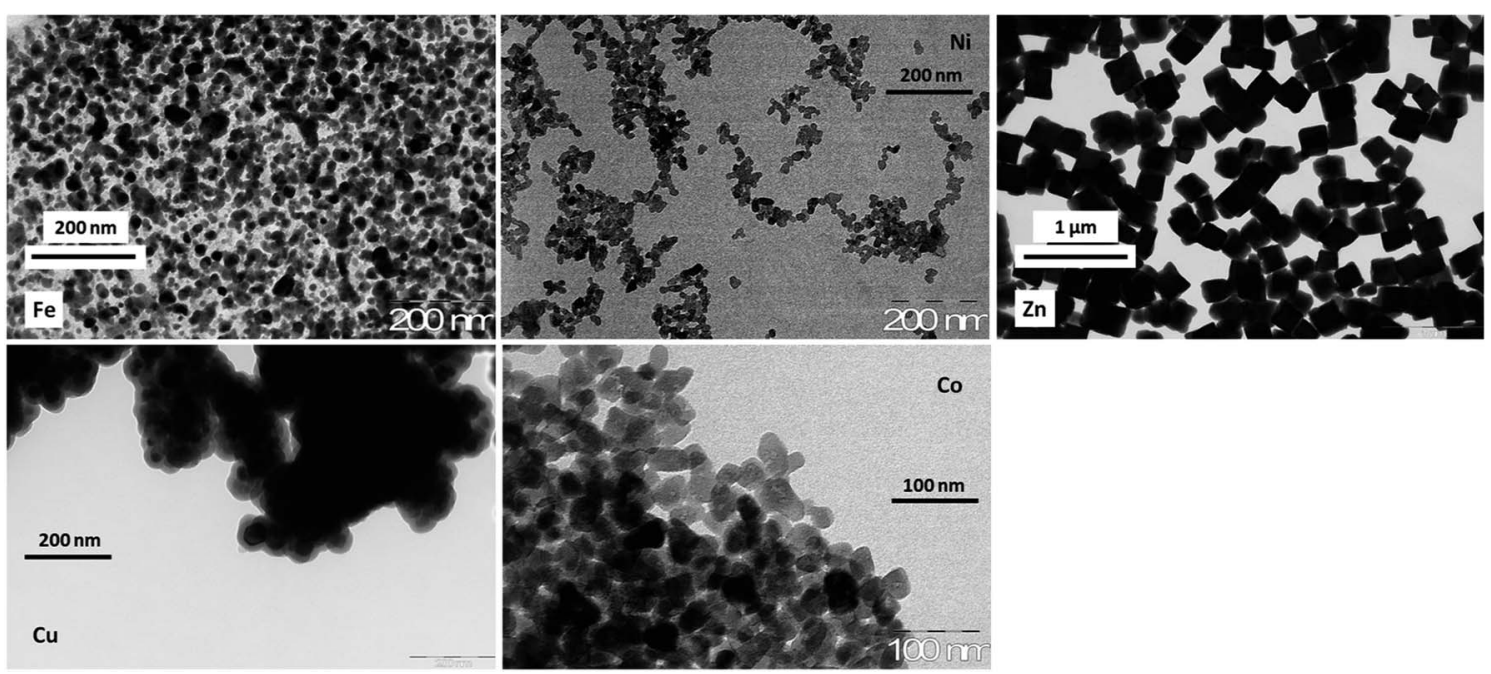

Fig. 1 TEM photographs of bulk particles of metal hexacyanoferrates. 

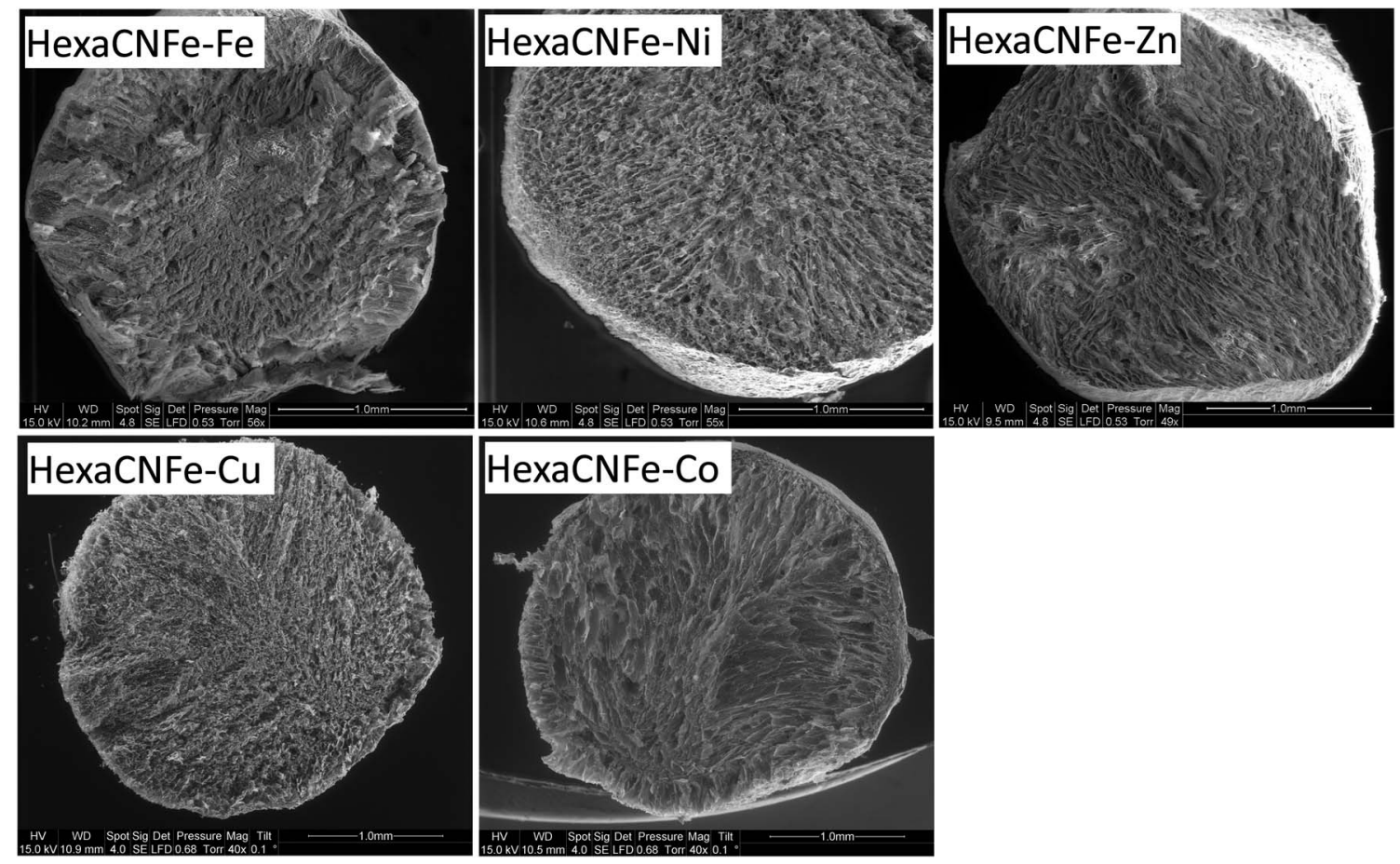

Fig. 2 SEM photographs of composite sorbents (metal-potassium hexacyanoferrates/chitin).
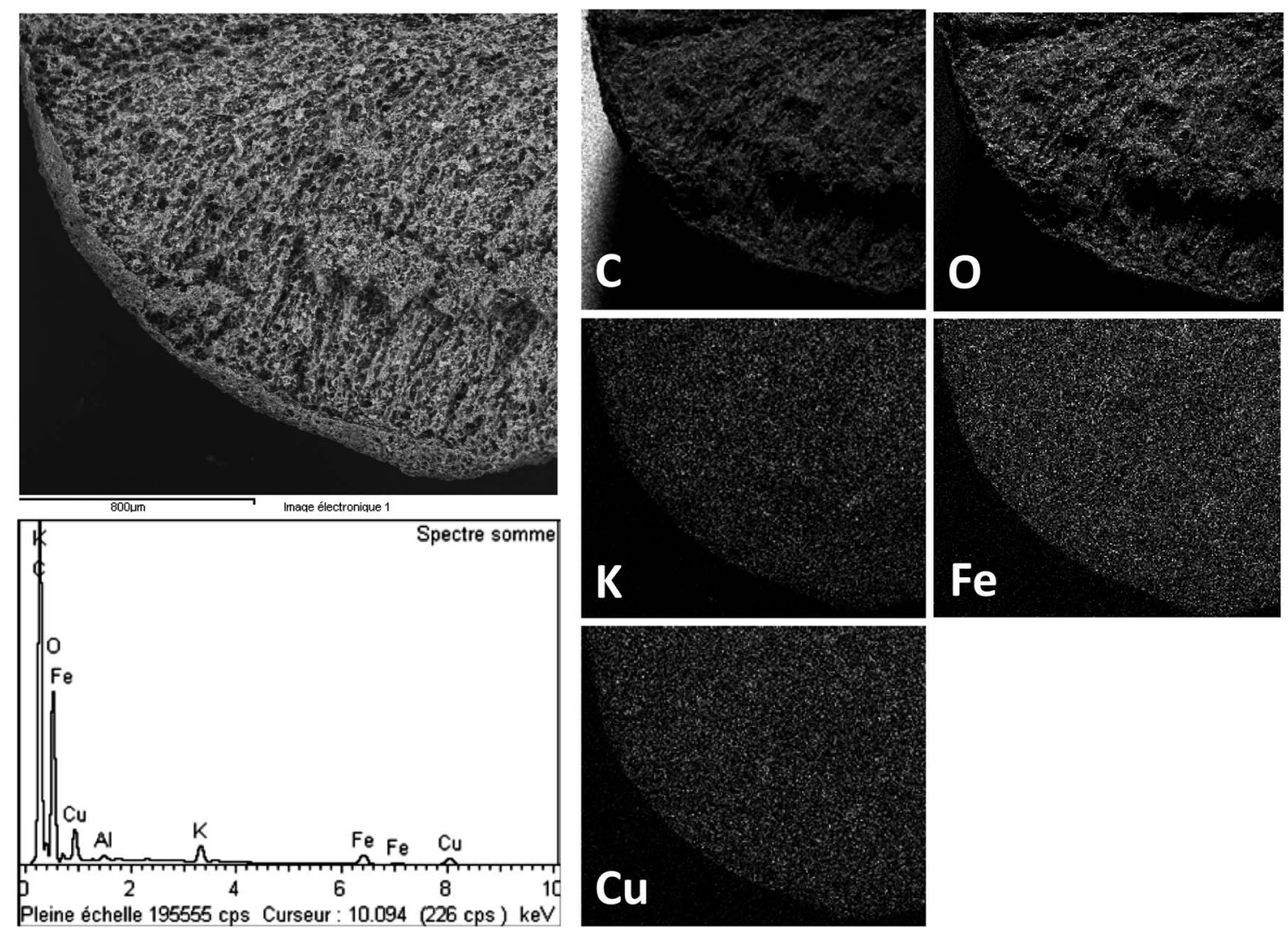

Fig. 3 SEM-EDX analysis of a cross-section of composite hexaCNF-Ni (SEM photograph, X-ray spectrum and distribution of elements: C, O, K, $\mathrm{Fe}$ and $\mathrm{Cu}$ ). 


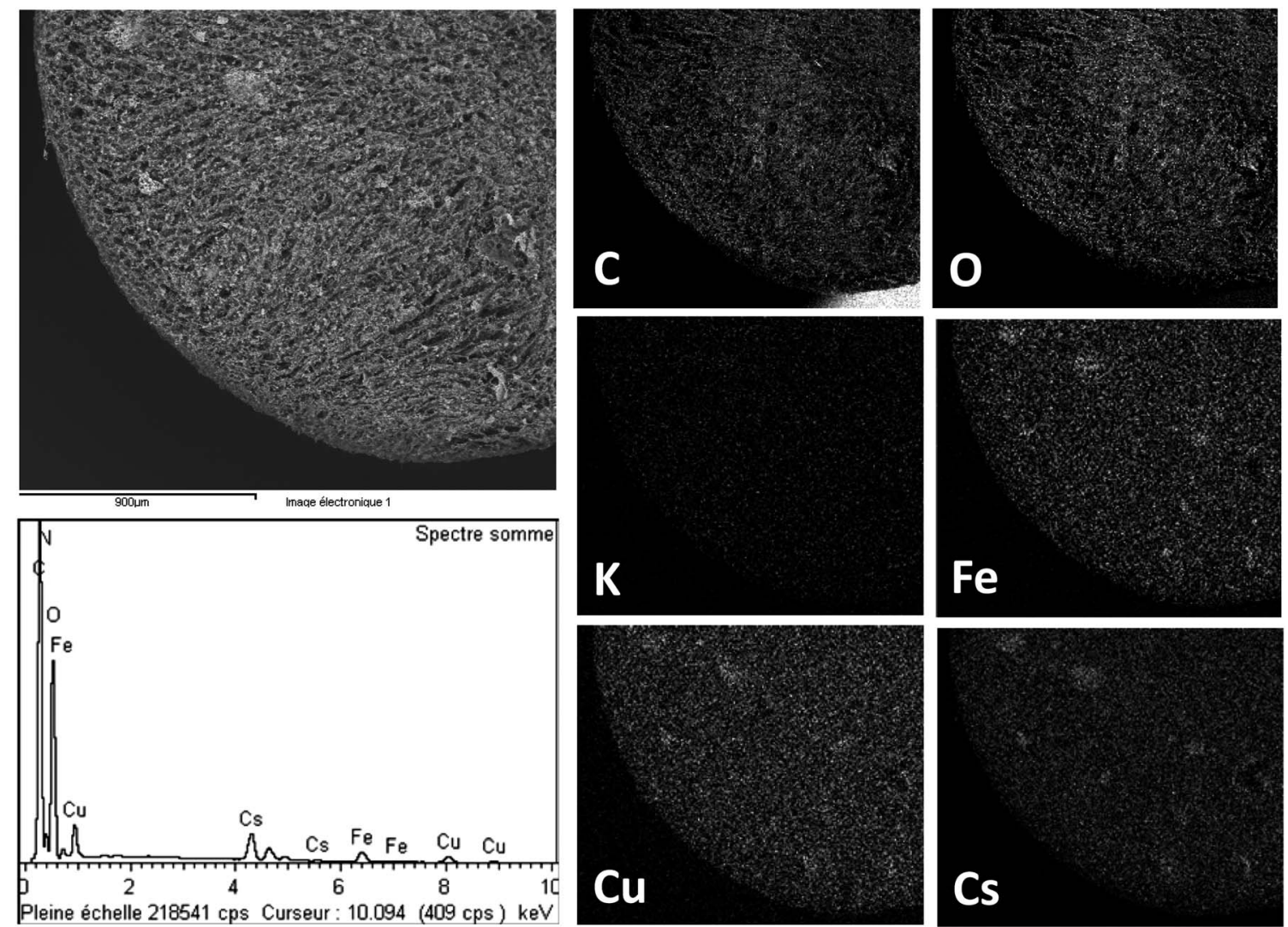

Fig. 4 SEM-EDX analysis of a cross-section of composite hexaCNF-Cu after Cs sorption (SEM photograph, X-ray spectrum and distribution of elements: C, O, K, Fe, Cu and Cs).

encapsulating material decreases the mass percentage of the ion-exchanger). However, despite these variations due to analysis focus, the figure clearly shows the disappearance of the signals for $\mathrm{K}$ with the appearance of the signals for Cs. This is another confirmation of the ion exchange mechanism between $\mathrm{K}(\mathrm{I})$ and $\mathrm{Cs}(\mathrm{I})$. Fig. AM4 (see the ESI $\dagger$ ) shows the same trends for the copper-potassium hexacyanoferrate/chitin composite: Cs replaced $\mathrm{K}$ on the EDX spectrum.

A subtle difference is observed in the case of the cobaltpotassium hexacyanoferrate/chitin composite: after Cs(I) sorption, both $\mathrm{K}$ and $\mathrm{Cs}$ are present on the X-ray diffraction spectrum. This is probably due to an incomplete saturation of the sorbent under selected experimental conditions. Similar trends are observed in Fig. AM5 (see the ESI $\dagger$ ) for the iron-potassium hexacyanoferrate/chitin composite: traces of $\mathrm{K}$ remained detectable in the X-ray spectra in the cross-section both on localized point analysis and in broad area analysis. Fig. AM6† compares the EDX spectra of the iron-potassium hexacyanoferrate/chitin composite for both spot (crystal zone) and large area analyses. As expected, some specific areas corresponding to small crystal agglomeration show more intense peaks for Fe and Cs. This clearly correlates the sorption of Cs to hexacyanoferrate-based materials. In this case again $\mathrm{K}$ remained on the sorbent: the material is not fully saturated.

These observations clearly show that the materials are homogeneous and that all reactive groups remained accessible due to the large macro-porosity of the composite materials. In addition, the X-ray diffraction spectra confirm that Cs(I) was exchanged with $\mathrm{K}(\mathrm{I})$.

The X-ray diffraction analysis of bulk metal-potassium hexacyanoferrate materials is reported in Fig. 5. While the Zncomplex showed very well resolved peaks, which means that the product is very crystalline (this is consistent with the TEM observations, Fig. 1), other metal complexes were characterized by the presence of broad and poorly resolved peaks. This could be attributed to three main reasons: (a) the poor crystalline structure (evidenced by the TEM observations), (b) the very small size of crystals (the $\mathrm{Zn}$ ion-exchanger was characterized by a much larger crystal size - about $250 \mathrm{~nm}$ - compared with few tens for other ion-exchangers, ${ }^{31}$ and (c) the co-existence of different $\mathrm{Kmetal}\left[\mathrm{Fe}(\mathrm{CN})_{6}\right]$ structures with various proportions of $\mathrm{K}$, metal and Fe (varying the proportion between the co-metal and potassium hexacyanoferrate moiety, contrary to the $\mathrm{Zn}$ complex, which appears to be mono-crystallized). By comparison with $\mathrm{X}$-ray diffraction bank data the zinc-complex appears to be very close to the $\mathrm{Zn}_{3} \mathrm{~K}_{2}\left[\mathrm{Fe}(\mathrm{CN})_{6}\right]_{2} \cdot 5 \mathrm{H}_{2} \mathrm{O}$ structure. The Fe-, $\mathrm{Ni}$-, Co-, and $\mathrm{Cu}-$ complexes showed very similar X-ray diffraction profiles with peaks around $2 \theta=17.5^{\circ}(200), 24.8^{\circ}(220), 35.3^{\circ}$ (400), $39.5^{\circ}(420), 43.6^{\circ}(422), 50.7^{\circ}(440), 53.8^{\circ}(600)$ and $57.3^{\circ}$ (620). These bands are consistent with the peaks observed on the nickel complex immobilized on polyacrylonitrile, ${ }^{22}$ on mesoporous silica, ${ }^{11}$ or on Prussian Blue immobilized in 

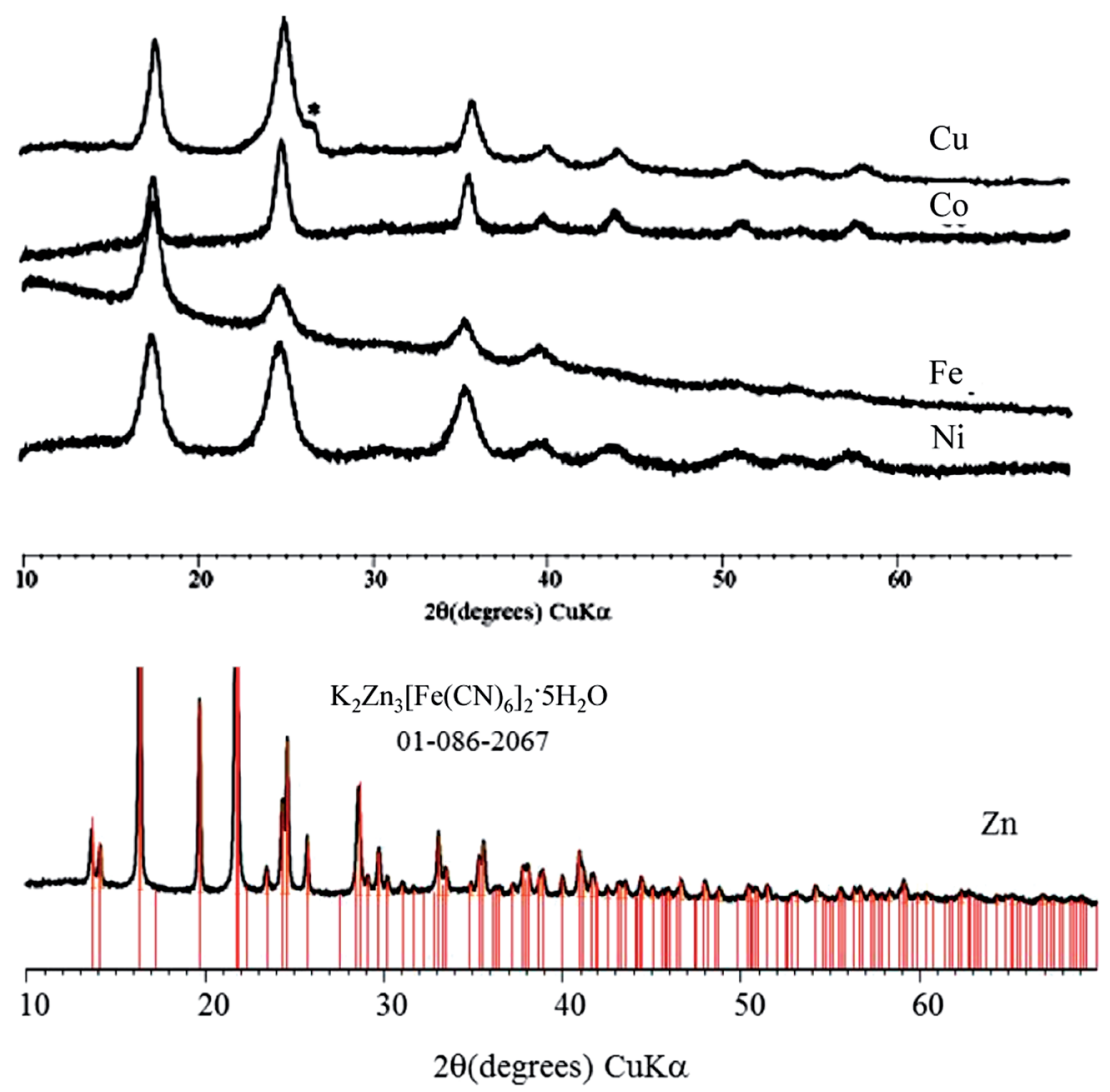

Fig. 5 X-ray diffraction analysis of bulk metal-potassium hexacyanoferrate complexes.

alginate capsules, ${ }^{18}$ though in these cases the peaks were much sharper than those observed with the present materials. Some additional peaks (compared to the reference spectra) could indicate that several analogues (with varying molar ratios between the hexacyanoferrate moiety and K/co-metal) may coexist in the final synthesized complexes.

The size $(s, \mathrm{~nm})$ of the crystals (for $\mathrm{Ni}^{-}, \mathrm{Fe}-\mathrm{CO}-\mathrm{Cnd} \mathrm{Cu}^{-}$ potassium hexacyanoferrate complexes) was roughly evaluated using the Scherrer equation:

$$
S=\frac{K \times \lambda}{\beta \times \cos \theta}
$$

where $K$ is a dimensionless factor depending on the shape of the crystals (varying between 0.9 and 1 , here taken as 0.95 ), $\lambda$ is the X-ray wavelength $\left(1.50406 \mathrm{~nm}\right.$, for $\left.\mathrm{Cu} \mathrm{K}_{\alpha}\right), \theta$ is the Bragg angle (position of the diffraction peak, $\operatorname{rad}$ ), and $\beta$ is the line broadening at half the maximum intensity (FWHM, full width at half maximum, rad).

The equation was applied to the three major peaks (i.e., at $2 \theta$ $=17.5^{\circ}, 25^{\circ}$ and $35^{\circ}$ ). The average values (and standard deviation) were: $8( \pm 1) \mathrm{nm}, 9( \pm 1) \mathrm{nm}, 14( \pm 2) \mathrm{nm}$ and $12( \pm 1) \mathrm{nm}$ for Ni-, Fe-, Co- and Cu-potassium hexacyanoferrate complexes, respectively. The Scherrer equation cannot be applied to large particles (larger than $0.1-0.2 \mu \mathrm{m}$ ); this is the reason for not applying the equation to the $\mathrm{Zn}$-potassium hexacyanoferrate complex. In addition, it is important to point out that the simplified Scherrer equation can only provide a rough evaluation of the size of complex nanoparticles (undervaluation of the true size of particles), but this is qualitatively consistent with the observations made from TEM pictures (Fig. 1): Ni and Fe-potassium hexacyanoferrate compounds being of the same order of magnitude and slightly lower in size than $\mathrm{Cu}-$ and $\mathrm{Co}^{-}$ potassium hexacyanoferrate ones.

Thermal degradation is an important criterion for the treatment of the material after metal loading (end of the life cycle). A test was performed on the Prussian Blue composite (see the ESI, $\uparrow$ Fig. AM7). A first weight loss (around 14\%) occurs in the range of $20-100{ }^{\circ} \mathrm{C}$; this corresponds to loss of water absorbed at the surface of the material. The second step in the process of degradation occurs between 100 and $550{ }^{\circ} \mathrm{C}$; this corresponds to the degradation of the biopolymer matrix (additional weight loss of $70 \%$; total weight loss close to $85 \%$ ). The thermogravimetric data (TG) are very similar to those shown for the non-isothermal degradation of chitin, ${ }^{32}$ though the end of the thermal degradation occurred at a lower temperature (around $550{ }^{\circ} \mathrm{C}$, vs. $780{ }^{\circ} \mathrm{C}$ in the case of pure chitin). In the case of lead hexacyanoferrate the thermal degradation represented a weight loss of $24 \%$ at $500{ }^{\circ} \mathrm{C}$ (and no more degradation occurred above $\left.500{ }^{\circ} \mathrm{C}\right) .{ }^{33}$ Though the inorganic compound is not identical to the present ion-exchangers it is roughly indicative of their thermal stability. It is interesting to observe that the thermal degradation of chitin leads to ashes representing about $10-20 \%$ of initial mass. ${ }^{32}$ Based on the composition of the Fe-composite (i.e., about $20 \%$ of the 
Table 1 Elemental analysis of composite sorbents (after mineralization)

\begin{tabular}{|c|c|c|c|c|c|}
\hline & HexaCNFe-Ni & HexaCNFe-Zn & HexaCNFe-Co & HexaCNFe-Cu & HexaCNFe-Fe (PB) \\
\hline$K^{a}$ & 0.782 & 0.486 & 0.851 & 0.472 & 0.154 \\
\hline Metal $^{a}$ & 1.004 & 0.780 & 0.710 & 0.894 & n.d. \\
\hline $\mathrm{Fe}^{a}$ & 0.605 & 0.565 & 0.533 & 0.535 & 1.572 \\
\hline $\mathrm{EIC}^{b}$ & $\mathrm{~K}_{1,29} \mathrm{Ni}_{1,66}\left[\mathrm{Fe}(\mathrm{CN})_{6}\right]$ & $\mathrm{K}_{0,86} \mathrm{Zn}_{1,38}\left[\mathrm{Fe}(\mathrm{CN})_{6}\right]$ & $\mathrm{K}_{1,60} \mathrm{Co}_{1,60}\left[\mathrm{Fe}(\mathrm{CN})_{6}\right]$ & $\mathrm{K}_{0,88} \mathrm{Cu}_{1,67}\left[\mathrm{Fe}(\mathrm{CN})_{6}\right]$ & $\mathrm{K}_{0,28} \mathrm{Fe}_{1,67}\left[\mathrm{Fe}(\mathrm{CN})_{6}\right]$ \\
\hline IEC $^{c}$ & 22 & 19 & 19 & 19 & $18^{C}$ \\
\hline $\mathrm{TEC}^{d}$ & 210 & 122 & 160 & 158 & n.d. \\
\hline
\end{tabular}

${ }^{a}$ Metal content in the composite (mmol metal ${ }^{-1}$ composite). ${ }^{b}$ "Equivalent" immobilized compound, EIC: on the basis of molar ratios of $K$, metal and Fe; hydration of the complexes was not evaluated. ${ }^{c}$ IEC: ion-exchanger content based on the EIC $(\%, \mathrm{w} / \mathrm{w}) .{ }^{d}$ Theoretical exchange capacity, TEC

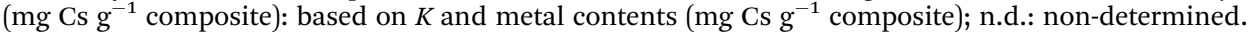

ion-exchanger in the composite, Table 1), the weight loss of the composite (close to $85 \%$ ) was consistent with the thermal degradation characteristics of the different components (chitin and ion-exchanger). With a chitin fraction of $80 \%$ (with a residual ash of about $15 \%$; i.e., a fraction of $12 \%$ in the residue) and an ion-exchanger fraction of $20 \%$ (with a residual ash of about $24 \%$; i.e., a fraction of $5 \%$ in the residue), the calculated weight loss should be close to $17 \%$.

The thermal decomposition of Prussian Blue immobilized in alginate capsules was reported to proceed through four successive steps: (a) in the range $30-250{ }^{\circ} \mathrm{C}$ : elimination of water both absorbed and constitutive of the hydration of Prussian Blue (6 $\mathrm{H}_{2} \mathrm{O}$ coordinating molecules per $\mathrm{PB}$ molecule), (b) in the range 250-350 ${ }^{\circ} \mathrm{C}$ : beginning of the degradation of the cyano group, (c) in the range $350-550{ }^{\circ} \mathrm{C}$ : degradation of intermediate products, and (d) above $500{ }^{\circ} \mathrm{C}$ : final degradation leading to $\mathrm{Fe}_{2} \mathrm{O}_{3} \cdot{ }^{18}$

\section{Sorbent characterization - chemical properties}

The samples were mineralized and the metal content was analyzed by ICP-AES for the determination of the probable structure of the complexes immobilized in the chitin matrix. Table 1 reports the results of the elemental analysis. The K/Fe and metal/Fe molar ratios were used to propose an "equivalent" structure for the complex. Taking into account the possibility that several complexes with different compositions may be co-synthesized it is difficult to establish a clear evidence for the structure of the produced compounds. The $\mathrm{K} / \mathrm{Fe}$ molar ratios were also used to calculate the possible structure of the compounds using the "model" structure $\mathrm{K}_{2 x} \mathrm{metal}_{2-x}\left[\mathrm{Fe}(\mathrm{CN})_{6}\right] .^{34}$ This theoretical equation does not fit experimental data when considering the metal/Fe molar ratio: this is probably related to the co-existence of different complexes. In addition, in the case of the synthesis and encapsulation of Prussian Blue, it was not possible to clearly evaluate iron in the hexacyanoferrate from the co-metal: evaluation of the structure was performed using the "model" structure. Another approximation was used for evaluating this structure, considering that in the other compound the iron content varied between 0.535 and $0.605 \mathrm{mmol} \mathrm{Fe} \mathrm{g}^{-1}$ composite (average value: $0.56 \mathrm{mmol} \mathrm{Fe} \mathrm{g}^{-1}$ composite) and deducing the

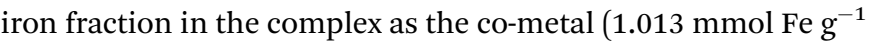
composite, by difference from the total iron content).
The hexacyanoferrate fraction (iron content) was used for calculating the mass fraction of the ion-exchanger in the composite materials: this fraction remained almost constant and close to $20 \%$ in weight (in the range 18 to $22 \%$ ). The potassium and the metal content was used to calculate the ion exchange capacity $(y+2 x)$ of composite materials based on the possible structure of binary hexacyanoferrate $\mathrm{K}_{y}$ metal ${ }_{x}$ (metal $\left.\left[\mathrm{Fe}(\mathrm{CN})_{6}\right]\right) \cdot{ }^{35}$ SEM-EDX analyses have confirmed that $\mathrm{Cs}(\mathrm{I})$ was exchanged with $\mathrm{K}(\mathrm{I})$. Since the potassium content strongly varied between the different composites (from 0.154 to 0.851 mmol $\mathrm{K} \mathrm{g}^{-1}$ composite), the theoretical exchange capacity

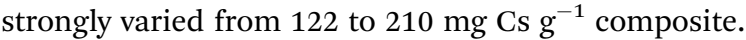

The composite materials constitute about $80 \%$ of chitin and $20 \%$ of metal-potassium hexacyanoferrate. The biopolymer matrix will thus bring a strong contribution to the FT-IR spectrum (see the ESI, $\uparrow$ Fig. AM8). The FT-IR spectra of chitosan and chitin are well documented. ${ }^{36}$ Major bands have been localized in the range of $3000-3600 \mathrm{~cm}^{-1}$ (OH stretching bands), 2850$2950 \mathrm{~cm}^{-1}$ (C-H stretching bands), around $1420 \mathrm{~cm}^{-1}\left(-\mathrm{CH}_{2}\right.$ bending), $850-1150 \mathrm{~cm}^{-1}$ (skeletal vibrations on the glucose ring and glucosidic linkage); more specific bands appear at 1655 $\mathrm{cm}^{-1}$ (amide I band), 1620-1640 $\mathrm{cm}^{-1}$ (-NH bending of $\mathrm{NH}_{2}$ ), around $1560 \mathrm{~cm}^{-1}$ (amide II band) and around $1320 \mathrm{~cm}^{-1}$ (amide III band). The presence of all these bands clearly demonstrates that chitosan was extensively re-acetylated, though the band at $1640 \mathrm{~cm}^{-1}\left(-\mathrm{NH}\right.$ bending of $\left.\mathrm{NH}_{2}\right)$ means that some amine groups are still present.

Hexacyanoferrate-based complexes are characterized by three main bands: (a) in the range $417-450 \mathrm{~cm}^{-1}$ (metal-CN stretching mode),$^{33}$ (b) around $590 \mathrm{~cm}^{-1}$ (Fe-CN deformation mode, for $\mathrm{Fe}(\mathrm{II})),{ }^{33}$ or $540 \mathrm{~cm}^{-1}$ (Fe-CN deformation mode, for $\mathrm{Fe}(\mathrm{III})$ ), ${ }^{37}$ and (c) $2090 \mathrm{~cm}^{-1}$ or $2160 \mathrm{~cm}^{-1}$ (CN stretching mode) for $\mathrm{Fe}(\mathrm{II}),{ }^{38}$ and $\mathrm{Fe}(\mathrm{III}),{ }^{37}$ respectively. The $\mathrm{CN}$ stretching mode was detected at $2067 \mathrm{~cm}^{-1}, 2091 \mathrm{~cm}^{-1}, 2094 \mathrm{~cm}^{-1}, 2100 \mathrm{~cm}^{-1}$ and $2083 \mathrm{~cm}^{-1}$, for metal-composites: Fe, Ni, $\mathrm{Zn}, \mathrm{Cu}$ and $\mathrm{Co}$, respectively (Fig. 6). The wavenumber of this vibration mode is strongly affected by the metal bound to the CN group; however, in all cases Fe was probably in the Fe(II) form. This is consistent with the appearance of a band around $600 \mathrm{~cm}^{-1}$ (deformation mode for Fe-CN, with Fe(II)), though a small shoulder (poorly resolved) was detected in some cases around $550 \mathrm{~cm}^{-1}$ (deformation mode for Fe-CN, with Fe(III)) (Fig. AM9, see the ESI $\dagger$ ). 


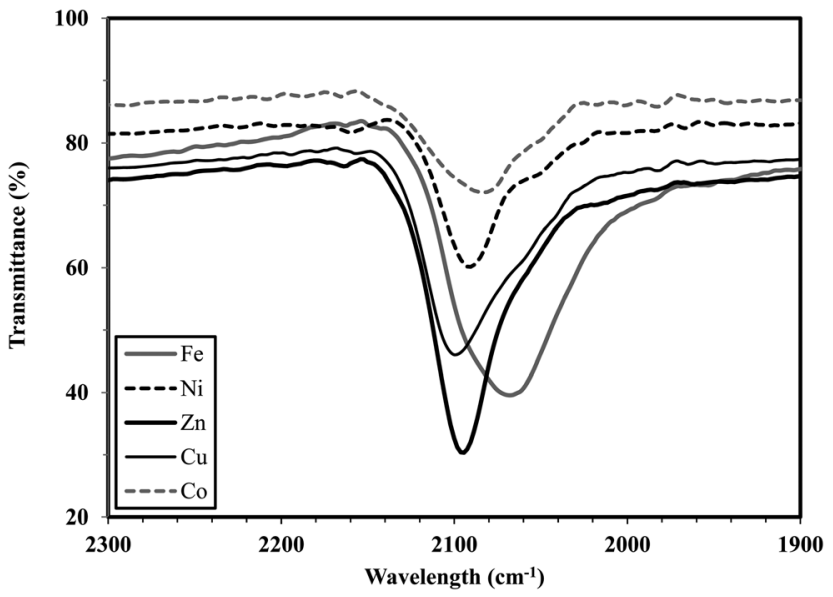

Fig. 6 FTIR spectra of metal-potassium hexacyanoferrates/chitin composites (in the $2100 \mathrm{~cm}^{-1}$ region; complete FTIR spectra are presented in the ESI, $\uparrow$ Fig. AM4).

It is noteworthy that a peak is observed at around $1728 \mathrm{~cm}^{-1}$. This peak does not correspond to hexacyanoferrate compounds and it is not present in the case of chitin. Carbonyl group compounds (such as carboxylic acids, ketones, aldehydes or

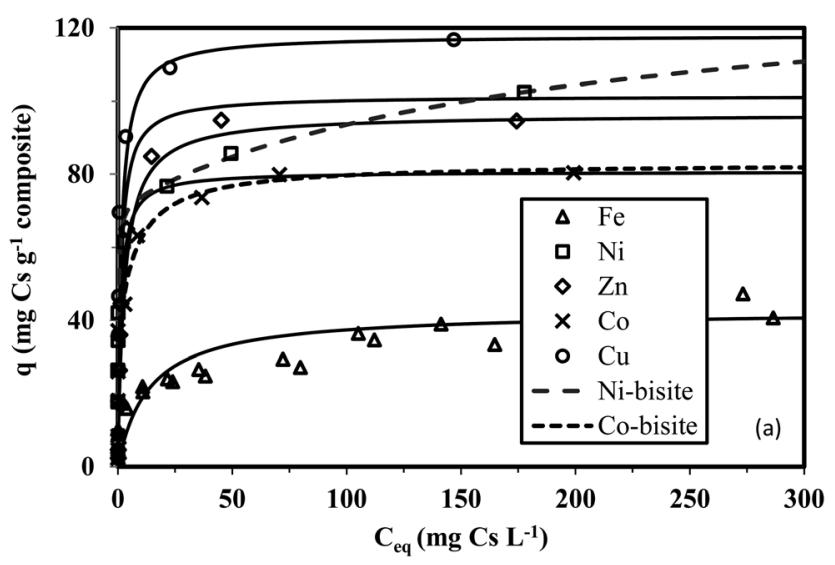

Fig. 7 Cs sorption isotherms on metal-potassium hexacyanoferrates/ chitin composites (solid lines show the modeling of sorption isotherms with the Langmuir equation and the parameters reported in Table 2, dashed lines show the modeling of $\mathrm{Ni}$ - and $\mathrm{Co}$-composites with the Langmuir bi-site model). esters) are generally identified by frequencies in the range of $1700-1750 \mathrm{~cm}^{-1}$. The appearance of this band can be probably attributed to chitosan reacetylation.

\section{Sorption performance}

Sorption isotherms show the distribution of the solute (i.e., $\mathrm{Cs}(\mathrm{I})$ ) between the solid phase $\left(q, \mathrm{mg} \mathrm{Cs}^{-1}\right.$ composite) and the aqueous phase $\left(C_{\text {eq }}, \mathrm{mg} \mathrm{Cs} \mathrm{L}^{-1}\right)$ at equilibrium. This is representative of the thermodynamic equilibrium and this can be usually described by the Langmuir (asymptotic trend) or the Freundlich (exponential trend, usually applicable for unsaturated experimental conditions). ${ }^{39}$ Fig. 7 shows Cs(I) sorption isotherms using the different metal potassium hexacyanoferrate/chitin composites.

The Langmuir equation:

$$
q=\frac{q_{\mathrm{m}} b C_{\mathrm{eq}}}{1+b C_{\mathrm{eq}}}
$$

where $q_{\mathrm{m}}$ (mg Cs $\mathrm{g}^{-1}$ composite) is the sorption capacity at equilibrium and at saturation of the monolayer and $b$ is the affinity coefficient $\left(\mathrm{L} \mathrm{mg}^{-1}\right)$.

All these curves are characterized by an asymptotic trend and by a saturation plateau, which is reached for residual concentrations depending on the composite materials. While the Fecomposite reached the saturation plateau for an equilibrium concentration close to or above $200 \mathrm{mg} \mathrm{Cs}^{-1}$, for the other materials the saturation occurs for concentrations ranging between 50 and $100 \mathrm{mg} \mathrm{Cs} \mathrm{L}^{-1}$. This is consistent with the comparison of affinity coefficients for the different materials (Table 2): $\mathrm{Co}^{-}>\mathrm{Ni}^{-}>\mathrm{Cu}^{-} \gg \mathrm{Zn}^{-} \ggg \mathrm{Fe}$-composite. The differences can be attributed to several reasons linked to the type of metal, but also the mode of synthesis of the ionexchanger (mode and velocity of introduction of the precursors). These parameters are currently under study.

Complementary experiments would be necessary to clarify the parameters to optimize for appropriate synthesis of ionexchangers, and their encapsulation. It is noteworthy that for both Ni- and Co-composites the Langmuir model fails to fit experimental data in the curved part of the plots: the Langmuir curves (solid lines) over-estimated sorption capacities. This phenomenon was less marked for other composite materials. A second model based on the Langmuir bi-site equation was tested. This model can be used for fitting experimental data

Table 2 Cs sorption isotherms using metal-potassium hexacyanoferrates/chitin composites ${ }^{b}$

\begin{tabular}{lcccccccr}
\hline HexaCNFe-metal $^{a}$ & $q_{\mathrm{m}}$ & $q_{\mathrm{m}}{ }^{*}$ & $b$ & $R^{2}$ & $q_{\mathrm{m} 1}$ & $b_{1}$ & $q_{\mathrm{m} 2}$ & $b_{2}$ \\
\hline Fe (0.15/20) & 42.45 & 235.8 & 0.074 & 0.890 & & & & \\
$\mathrm{Ni}(0.78 / 104)$ & 101.4 & 461.1 & 0.745 & 0.903 & 71.8 & 5.04 & 63.8 & 0.0052 \\
Zn (0.49/65) & 96.4 & 507.5 & 0.355 & 0.972 & & & 0.988 \\
Co $(0.85 / 113)$ & 80.7 & 424.7 & 0.827 & 0.904 & 34.2 & 14.28 & 48.8 & 0.137 \\
Cu (0.47/63) & 117.9 & 620.6 & 0.667 & 0.878 & & & 0.913
\end{tabular}

${ }^{a}$ In parentheses ( $K$ content of the composites, mmol K g ${ }^{-1}$ composite/theoretical sorption capacity, $\mathrm{mg}^{\mathrm{Cs}} \mathrm{g}^{-1}$ composite). $^{b} q$ : sorption capacity (mg Cs $\mathrm{g}^{-1}$ material: either composite or ion-exchanger); $b$ : affinity coefficient $\left(\mathrm{L} \mathrm{mg}^{-1}\right)$. 
when the sorption occurs on two different sites (with different sorption energies), or when different metal species can be bound on the sorbent. ${ }^{17}$ This would be consistent with the possibility of co-existence of different materials in the encapsulated material: the synthesis procedure may generate different ion exchangers in terms of the composition (K/metal ratio) or particle size, which, in turn, may affect their reactivity.

The Langmuir bi-site equation:

$$
q=\frac{q_{\mathrm{m}, 1} b_{1} C_{\mathrm{eq}}}{1+b_{1} C_{\mathrm{eq}}}+\frac{q_{\mathrm{m}, 2} b_{2} C_{\mathrm{eq}}}{1+b_{2} C_{\mathrm{eq}}}
$$

where $\left(q_{\mathrm{m}, 1}, b_{1}\right)$ and $\left(q_{\mathrm{m}, 2}, b_{2}\right)$ are the parameters for the two types of sorption sites.

The affinity coefficients $\left(b_{1}\right.$ and $\left.b_{2}\right)$ may be significantly different reflecting the differences in the strength of interaction of the solute with these different sorption sites (or different metal species). Table 2 reports the constants: the maximum sorption capacities were of the same order of magnitude while the affinity coefficients were much lower for the second sorption sites (by more than 2 orders of magnitude). The modeled curves appear as dotted lines in Fig. 7.

The maximum sorption capacities (corresponding to the saturation of the monolayer) also strongly varied with the metalcomposite: $\mathrm{Cu}->\mathrm{Ni}->\mathrm{Zn}->\mathrm{Co}-\gg$ Fe-composite. These values are miscorrelated with the potassium content. Comparison of the maximum sorption capacities with the theoretical ion exchange capacities, calculated on $\mathrm{K}$ and metal contents (see above in Table 1), shows that only about $50 \%$ of the theoretical sorption is obtained for $\mathrm{Ni}$ - and Co-composites and up to $75 \%$ for $\mathrm{Zn}$ - and $\mathrm{Cu}$-composites. These results could probably be explained by some difficulties in accessing some ion-exchange sites. In addition, the co-existence of different compounds produced during the synthesis of the ion-exchanger may affect the theoretical structure of the ion-exchangers and then their ion-exchange capacities may explain these discrepancies. The Cs(I) sorption capacities found in the present study are comparable to the best values obtained for the immobilization of metal-potassium hexacyanoferrates in the literature (Table 3).

Table 2 also reports the maximum sorption capacities as a function of the actual amount of the ion-exchanger in the composite materials. This allows classification of the different materials, in terms of rational use of the ion-exchanger, into three groups:

(a) most efficient sorbent: Cu-composite,

(b) intermediary group: $\mathrm{Ni}-$, Co-, and $\mathrm{Zn}$-composite (with almost identical sorption capacities), and

(c) less efficient sorbent: Fe-composite.

This is consistent with the ranking of sorbents based on corrected maximum sorption capacities (in $\mathrm{mg} \mathrm{Cs} \mathrm{g}^{-1}$ ionexchanger) appearing in Table 2. These values can be compared to those obtained in the Cs co-precipitation process (and the subsequent flotation technique) with the $\mathrm{Zn}$-composite, ${ }^{\mathbf{4 0}}$ and Fe-composite, ${ }^{1}$ i.e., 372 and $715 \mathrm{mg} \mathrm{Cs}^{-1}$ metal complex.

The discrepancies between maximum theoretical values and experimental values (and more specifically for the cases corresponding to underestimated sorption capacities) may also be explained by the accessibility and availability of functional reactive sites. Indeed, in the case of an excess of ion-exchanger some functional groups could be aggregated, agglomerated or more packed making the use of these reactive groups less available for Cs(I) sorption. In order to evaluate the impact of this "packing effect" some beads containing decreasing amounts of Prussian Blue (Fe-composite; with ion-exchanger loads of $18 \%$ (reference, Fe: 1/1), 9\% (Fe: 1/2) and 6\% (Fe: 1/3)) have been prepared and tested for Cs(I) sorption under identical experimental conditions. The results are summarized in

Table 3 Some examples of sorption capacities obtained for Cs(I) recovery using metal-potassium hexacyanoferrate complexes immobilized on different supports ${ }^{a}$

\begin{tabular}{|c|c|c|c|}
\hline Co-metal & Support & Sorption capacity (mg Cs $\mathrm{g}^{-1}$ composite)* & Reference \\
\hline $\mathrm{Ni}$ & Silica gel & $15-74$ & 31 \\
\hline $\mathrm{Ni}$ & Algal biomass & 25-199 & 46 \\
\hline $\mathrm{Ni}$ & Chitin disc & 80 & 20 \\
\hline $\mathrm{Ni}$ & Chitin & 101 & This study \\
\hline $\mathrm{Cu}$ & Activated carbon & 6 & 48 \\
\hline $\mathrm{Cu}$ & Polyethersulfone (PES) & 7 & 8 \\
\hline $\mathrm{Cu}$ & Chitosan & $130-260$ & 50 \\
\hline $\mathrm{Cu}$ & Chitin & 118 & This study \\
\hline $\mathrm{Fe}$ & Poly(methyl methacrylate) (PMMA) & 20 & 51 \\
\hline$F e^{*}$ & Co-precipitation process/bulk complex & 715 & 1 \\
\hline $\mathrm{Fe}$ & Chitin & 42 & This study \\
\hline $\mathrm{Zn}$ & Chitin & 96 & This study \\
\hline
\end{tabular}

${ }^{a}$ Italics: data concerning the co-precipitation process using bulk metal hexacyanoferrate complexes $\left(q, \mathrm{mg}^{\mathrm{Cs}} \mathrm{g}^{-1}\right.$ complex). 
Fig. AM10 (see the ESI $\dagger$ ). As expected increasing the amount of ion-exchanger increases sorption capacities (Fig. AM10a $\dagger$ ); however, the plot of sorption capacity as a function of the ionexchanger content (Fig. AM10b $\dagger$ ) leads to contrasting results. Indeed, while the standard and the half-content (of ionexchanger) curves almost overlapped, in the case of the composite whose ion-exchanger load was divided by a factor of 3 the sorption capacity was significantly increased (by 50 to $70 \%$ ). This means that the "dilution" of the ion-exchanger in the biopolymer matrix allows a more rational use of ion-exchanger capabilities. This is confirmed by the comparison of the maximum sorption capacity (saturation of the monolayer) reported as a function of the ion-exchanger content $\left(\mathrm{mg} \mathrm{Cs} \mathrm{g}^{-1}\right.$ ion-exchanger) in Table 4.

It is noteworthy that despite the presence of sodium nitrate in the solutions (as a background salt) significant changes were observed in the final $\mathrm{pH}$ of the solution (not controlled during the sorption). The initial $\mathrm{pH}$ varied for all salts between 5.6 and 6.5 , depending on the metal concentration. After sorption, the $\mathrm{pH}$ generally decreased by $1-1.5 \mathrm{pH}$ unit for the Fe- and $\mathrm{Zn}$ composite, by $0.5-1 \mathrm{pH}$ unit for the $\mathrm{Ni}$ - and $\mathrm{Cu}$-composite and tended to slightly increase for the Co-composite. The $\mathrm{pH}$ variation may be associated with acid-base properties of the biopolymer matrix. The amine groups of chitosan (remaining functions not reacetylated and acetylated amine groups) can bind protons.

Uptake kinetics have been compared for the different metalpotassium hexacyanoferrate complexes in their different forms (i.e., bulk, after chitosan stabilization (CSC), and encapsulated in chitin beads of two different sizes: large beads $(3.5 \mathrm{~mm})$ and small beads ( $2 \mathrm{~mm})$ ) (Fig. 8). The comparison of the different kinetic profiles (obtained with comparable amounts of ionexchanger; i.e., $20 \mathrm{mg}$ of ion-exchanger or $100 \mathrm{mg}$ of composite) allows evaluation of (a) the effect of encapsulation on mass transfer and on complex stability, (b) the potential effect on the metal associated with the potassium hexacyanoferrate moiety.

The first panel (i.e., kinetic profiles for bulk materials) provides two important pieces of information: (a) poor sorption efficiency (under the best conditions, Cs(I) removal did not exceed $20 \%$ ), and (b) relative instability (as evidenced by the progressive release of $\operatorname{Cs}(\mathrm{I})$ at a large contact time). The poor efficiency can be associated with the difficulty in separating the solid from the solution by filtration: the loss of complex nanoparticles (loaded with $\mathrm{Cs}(\mathrm{I})$ ) induces a loss of metal and an overestimation of Cs concentration. As expected the trend for the Fe-complex was less favorable than for other composites, due to the lowest sorption efficiency of this material (as observed with composite materials).

The second panel (i.e., kinetic profiles for chitosan stabilized complexes, CSC) clearly shows that chitosan stabilization (which significantly improved the velocity and efficiency of solid/liquid separation and filtration) enhanced the sorption performance of the hexacyanoferrate compounds. As expected $\mathrm{Fe}-\mathrm{CSC}$ was less favorable than other materials both in terms of equilibrium (metal recovery did not exceed $5-10 \%$, versus $30-$ $35 \%$ under comparable experimental conditions) and in terms of stability. Indeed, while for other metal-CSC the sorption
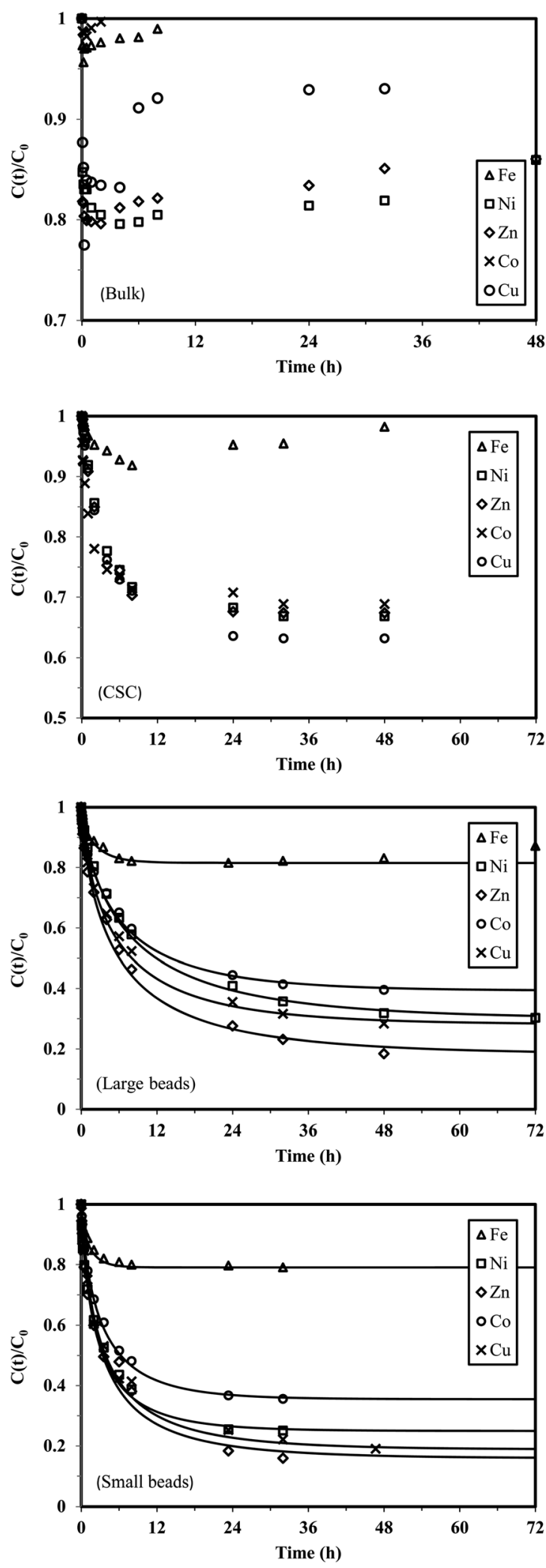

Fig. 8 Cs(I) uptake kinetics with metal-potassium hexacyanoferrate complexes (bulk, chitosan stabilized complexes, encapsulated in large and small beads) ( $C_{0}: 10 \mathrm{mg} \mathrm{Cs} \mathrm{L}^{-1} ; \mathrm{v}$ : $270 \mathrm{rpm}$; sorbent dosage: $20 \mathrm{mg}$ ion-exchanger $\mathrm{L}^{-1}$ or $100 \mathrm{mg}$ composite $\mathrm{L}^{-1}$; solid lines show kinetic modeling using the Crank equation and diffusion coefficients reported in Table 5). 
Table 4 Cs sorption isotherms using Fe-potassium hexacyanoferrates/chitin composites with different loads of ion-exchanger (1: 1: reference; $1: 2$ : halved load; $1: 3$ : load divided by 3)

\begin{tabular}{lllr}
\hline HexaCNFe-Fe $^{a}$ & $q_{\mathrm{m}}\left(\mathrm{mg} \mathrm{Cs} \mathrm{g}^{-1}\right.$ composite $)$ & $q_{\mathrm{m}}{ }^{a}\left(\mathrm{mg} \mathrm{Cs} \mathrm{g}^{-1}\right.$ ion-exchanger $)$ & $b\left(\mathrm{~L} \mathrm{mg}^{-1}\right)$ \\
\hline $1: 1(18 \% \mathrm{w} / \mathrm{w})$ & 44.1 & 244.8 & 0.074 \\
$1: 2(9 \% \mathrm{w} / \mathrm{w})$ & 24.0 & 266.8 & 0.068 \\
$1: 3(6 \% \mathrm{w} / \mathrm{w})$ & 23.2 & 386.0 & 0.964 \\
& & 0.984 & 0.963
\end{tabular}

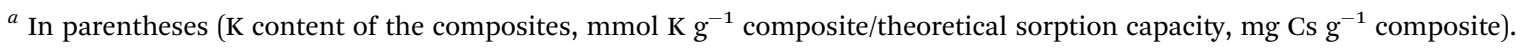

tended to stabilize after 24 hours of contact, with Fe-CSC Cs(I) release occurred after 12 hours of contact. The differences between $\mathrm{Ni}-$, $\mathrm{Zn}-$, Co- and $\mathrm{Cu}-\mathrm{CSC}$ were negligible in terms of kinetic profiles. About $50 \%$ of the total sorption occurred within the first 2 hours of contact, while 8 hours were sufficient to achieve $90 \%$ of total sorption.

The third and fourth panels compare the kinetic profiles for composite materials at different sizes. Fe-composites are much less efficient than other metal-composites: Cs(I) recovery did not exceed $20 \%$ and in the case of large beads after 24 hours of contact a slight release of Cs(I) could be observed. For the other metal-composites the differences between large and small beads were limited but significant. This means that intraparticle diffusion probably plays a role in the control of mass transfer. The pseudo-second order rate equation (PSORE) is frequently used for modeling uptake kinetics: ${ }^{\mathbf{4 1}}$

$$
\frac{\mathrm{d} q}{\mathrm{~d} t}=k_{2}\left(q_{\mathrm{m}, \text { calc. }}-q\right)^{2}
$$

with $k_{2}\left(\mathrm{~g} \mathrm{mg}^{-1} \mathrm{~min}^{-1}\right)$ being the apparent pseudo-second order

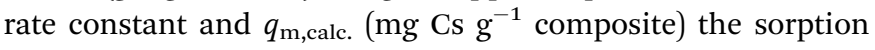
capacity at equilibrium.

After integration and setting with the boundary conditions, eqn (4a) can be linearized according to

$$
\frac{t}{q}=\frac{1}{k_{2} \times q_{\mathrm{m}, \text { calc. }^{2}}}+\frac{t}{q_{\mathrm{m}, \text { calc. }}}
$$

This model was applied for simulating the kinetic profiles for composites (Table 5); the discrepancies due to Cs(I) release and loss of Cs-loaded nano/microparticles, for bulk materials, during the filtration step did not allow us to obtain appropriate profiles for this model. The PSORE equation was globally appropriate for modeling experimental curves, based on the correlation coeffi-

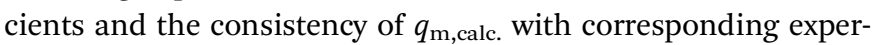
imental values $\left(q_{\mathrm{m} \text {,exp }}\right)$. In most cases, the calculated value $(q$ m,calc. $)$ slightly overestimated the experimental sorption capacity at equilibrium. The comparison of the apparent pseudo-second order rate coefficients $\left(k_{2}\right)$ for large and small beads confirms the discussion of kinetic profiles (Fig. 8): the kinetic rate was slightly higher for small beads than for large beads. This can be attributed to the limitations of the mass transfer rate when increasing the diameter of the beads. While for $\mathrm{Zn}$-, Co- and $\mathrm{Cu}$-composites the variation in the coefficient did not exceed $50 \%$, for $\mathrm{Fe}$ - and $\mathrm{Ni}$-composites the reduction of the size of the beads led to a doubling of the apparent pseudosecond order rate coefficient (Table 5). Nevertheless, the differences were not very marked and for all 5 sorbents (and the two different sizes) the $k_{2}$ coefficient remained in the range $0.48 \times$ $10^{-2}-4 \times 10^{-2} \mathrm{~g} \mathrm{mg}^{-1} \mathrm{~min}^{-1}$. The direct comparison of kinetic parameters with the literature may be difficult since the experimental conditions $(\mathrm{pH}$, particle size, metal concentration, ionexchanger load) may substantially influence the sorption kinetics. However, this may be helpful for, at least, comparing the orders of magnitude. In the case of the nickel-potassium hexacyanoferrate complex the PSORE coefficient reached $1.60 \times$

\begin{tabular}{|c|c|c|c|c|c|c|c|}
\hline \multirow[t]{2}{*}{$\mathrm{Fe}$} & LB & 16.8 & 16.8 & 1.73 & 0.997 & 49.1 & 0.11 \\
\hline & SB & 17.7 & 17.9 & 3.99 & 0.999 & 25.8 & 0.05 \\
\hline $\mathrm{Ni}$ & LB & 58.2 & 60.6 & 0.48 & 0.995 & 5.1 & 0.01 \\
\hline & SB & 71.9 & 74.6 & 0.98 & 0.991 & 2.2 & 0.03 \\
\hline \multirow[t]{2}{*}{ Co } & LB & 51.6 & 54.0 & 0.64 & 0.992 & 8.4 & 0.01 \\
\hline & SB & 55.1 & 57.5 & 1.09 & 0.996 & 4.7 & 0.01 \\
\hline \multirow[t]{2}{*}{$\mathrm{Cu}$} & LB & 61.4 & 63.7 & 0.65 & 0.994 & 6.7 & 0.01 \\
\hline & SB & 68.8 & 70.9 & 0.89 & 0.998 & 2.4 & 0.01 \\
\hline
\end{tabular}

Table 5 Cs(I) uptake kinetics - modeling of experimental data with PSORE and RIDE (Crank equation) (large beads: LB; small beads: SB)

${ }^{a}$ SSR: sum of squared residuals. 
$10^{-1} \mathrm{~g} \mathrm{mg}^{-1} \mathrm{~min}^{-1}$ when immobilized on PAN, ${ }^{22}$ and up to $6.8 \times$ $10^{-1} \mathrm{~g} \mathrm{mg}^{-1} \min ^{-1}$ when supported on mushroom biomass. ${ }^{42}$ In the case of Prussian Blue immobilized in alginate capsules the PSORE coefficient did not exceed $0.6 \times 10^{-3} \mathrm{~g} \mathrm{mg}^{-1} \mathrm{~min}^{-1} \cdot{ }^{18}$ For copper-potassium hexacyanoferrate encapsulated in PES the PSORE coefficient decreased when increasing the cesium concentration (in the range of 4 to $18 \mathrm{mg} \mathrm{Cs} \mathrm{L}^{-1}$ ) from $1.93 \times$ $10^{-1} \mathrm{~g} \mathrm{mg}^{-1} \mathrm{~min}^{-1}$ to $2.2 \times 10^{-2} \mathrm{~g} \mathrm{mg}^{-1} \mathrm{~min}^{-1} .^{8}$ This means that the different composites elaborated in this study are in the middle range of the other composites cited in the literature.

In the case of the iron-potassium hexacyanoferrate/chitin composite, different lots of beads have been prepared with decreasing of the ion-exchanger in the composite material. The previous section showed that the "dilution" of the ion-exchanger in the capsule improved its rational use for Cs(I) sorption. These materials have been tested and compared for Cs(I) uptake kinetics, while maintaining the ion-exchanger dosage constant (and varying the composite dosage). The kinetic profiles overlapped (see the ESI, $\dagger$ Fig. AM11). This means that, in terms of kinetics (including the reaction rate and diffusion characteristics), the load of ion exchanger did not influence mass transfer properties or reactivity of the composite material.

The encapsulation of the ion-exchanger leads to the confinement of micro- and nano-particles but at the expense of a possible limitation in mass transfer properties if the porosity of the matrix is not controlled. In such a case the mass transfer of Cs(I) will be controlled by a succession of diffusion mechanisms including (a) bulk diffusion (which can be neglected, providing a sufficient agitation of the solution), (b) external diffusion through the film surrounding the sorbent particles, and (c) intraparticle diffusion (RIDE, resistance to intraparticle diffusion equation). These different mechanisms generally take place simultaneously and should be taken into account together with the sorption isotherm (which control the local and instantaneous equilibrium at the surface of the sorbent) for the exact modeling of mass transfer. ${ }^{39}$ In a simplified approach the Crank equation can be used for roughly evaluating the intraparticle diffusion coefficient $\left(D_{\mathrm{e}}, \mathrm{m}^{2} \mathrm{~min}^{-1}\right):^{43}$

$$
\frac{q(t)}{q_{\mathrm{eq}}}=1-\sum_{n=1}^{\infty} \frac{6 \alpha(\alpha+1) \exp \left(\frac{-D_{\mathrm{e}} q_{\mathrm{n}}^{2} t}{r^{2}}\right)}{9+9 \alpha+q_{\mathrm{n}}^{2} \alpha^{2}}
$$

$q(t)$ and $q_{\text {eq }}$ are the concentrations of the metal in the resin at time $t$ and equilibrium, respectively, $r$ is the radius of the particle, and $q_{\mathrm{n}}$ the non-zero roots of the equation:

$$
\tan q_{\mathrm{n}}=\frac{3 q_{\mathrm{n}}}{3+\alpha q_{\mathrm{n}}^{2}}
$$

with

$$
\frac{q}{V C_{0}}=\frac{1}{1+\alpha}
$$

The Mathematica ${ }^{\mathrm{TM}}$ software was used for the determination of the intraparticle diffusion coefficient, $D_{\mathrm{e}}$ (Table 5). Fig. 8 shows that the RIDE well fits experimental data for the beads (both large and small particles, bold lines). The trend of the
Fe-composite to reach the equilibrium faster (though to a much lower level of sorption, as shown by the sorption yield that did not exceed $20 \%$ ) is confirmed by the value of the intraparticle diffusion coefficient that was about one order of magnitude higher than the levels reached with the other composites: 2.6-4.9 $\times 10^{-9} \mathrm{~m}^{2} \mathrm{~min}^{-1}$ (depending on the size of the beads) versus 2.4$8.4 \times 10^{-10} \mathrm{~m}^{2} \mathrm{~min}^{-1}$ for other composites. This is about $2-3$ orders of magnitude lower than the diffusivity of $\operatorname{Cs}(\mathrm{I})$ in water $\left(D_{0}(\operatorname{Cs}(\mathrm{I})): 1.23 \times 10^{-7} \mathrm{~m}^{2} \mathrm{~min}^{-1}\right) .{ }^{44}$ Systematically, the apparent intraparticle diffusion coefficient slightly decreased when decreasing the size of sorbent particles. This could be explained by the contribution of other diffusion mechanisms and/or by the partial heterogeneity of the material (external layers vs. core material with different diffusion characteristics). These values are significantly higher than those cited for Cs(I) diffusion into AMP-aluminosilicate microspheres (AMP: ammonium molybdophosphate; around $\left.4.8 \times 10^{-12} \mathrm{~m}^{2} \mathrm{~min}^{-1}\right),{ }^{45}$ and comparable to those found for $\mathrm{Cs}(\mathrm{I})$ sorption on nickel-potassium hexacyanoferrate/PAN composite beads $\left(1.6-4.5 \times 10^{-10} \mathrm{~m}^{2} \mathrm{~min}^{-1}\right){ }^{22}$

The tests performed on ${ }^{137} \mathrm{Cs}$ solutions are reported in Table 6. The sorption capacities ranged between $34 \times 10^{3}$ and $40 \times$ $10^{3} \mathrm{~Bq} \mathrm{~g}^{-1}$ composite, under selected experimental conditions (unsaturated levels). The removal efficiency (based on $\gamma$ counting) systematically exceeded $99.3 \%$ (for the $\mathrm{Zn}$-composite, the "less efficient") and up to $99.97 \%$ (for the Co-composite, the most efficient). Taking into account the actual ion-exchanger content of all composites the sorption capacities ranged from $153609 \mathrm{~Bq} \mathrm{~g}^{-1}$ ion-exchanger (for the Ni-composite) to 218089 $\mathrm{Bq} \mathrm{g}^{-1}$ ion-exchanger (for the Fe-composite). Comparing the distribution coefficients and decontamination factors, the sorbents can be ranked as $\mathrm{Zn}^{-}<\mathrm{Ni}^{-} \ll \mathrm{Cu}^{-}<\mathrm{Fe}-\ll \mathrm{Co}^{-}$ composite. Fe-, $\mathrm{Cu}^{-}$and Co-composites are quite efficient sorbents for ${ }^{137} \mathrm{Cs}$ recovery. The values of the decontamination factor and distribution coefficient for the Ni-composite are of the same order of magnitude as the values obtained with Nipotassium hexacyanoferrate immobilized in chitosan foams, under similar experimental conditions. ${ }^{20}$ This means that the other metal composites (especially $\mathrm{Fe}-\mathrm{Cu}$ - and Co-potassium hexacyanoferrate/chitin) have significantly higher levels of decontamination.

In addition, it is noteworthy that most of $\mathrm{Cs}(\mathrm{I})$ recovery proceeds through ion exchange with $\mathrm{K}(\mathrm{I})$; however, a small amount of the co-metal on the ion-exchanger can be exchanged. Some of these metal ions are toxic, though their toxicity is less

Table $6{ }^{137} \mathrm{Cs}$ sorption tests using metal-potassium hexacyanoferrates/chitin composites (initial activity, $A_{0}$ : $37000 \mathrm{~Bq} \mathrm{~L}^{-1}$ )

\begin{tabular}{lcccr}
\hline HexaCNFe-metal & $A_{\mathrm{f}}\left(\mathrm{Bq} \mathrm{L}^{-1}\right)$ & $q\left(\mathrm{~Bq} \mathrm{~g}^{-1}\right)$ & $K_{\mathrm{d}}\left(\mathrm{L} \mathrm{g}^{-1}\right)$ & $\mathrm{DF}^{a}$ \\
\hline $\mathrm{Fe}$ & 21 & 39256 & 1869 & 1762 \\
$\mathrm{Ni}$ & 97 & 33794 & 348 & 381 \\
$\mathrm{Zn}$ & 234 & 37903 & 162 & 158 \\
$\mathrm{Co}$ & 12 & 39944 & 3329 & 3083 \\
$\mathrm{Cu}$ & 31 & 33979 & 1096 & 1194
\end{tabular}

${ }^{a}$ DF: decontamination factor $\left(A_{0} / A_{\mathrm{f}}\right) ; K_{\mathrm{d}}\left(\mathrm{L} \mathrm{g}^{-1}\right): \mathrm{Cs}_{\text {sorbent }} / \mathrm{Cs}_{\text {solution }}$ at equilibrium. 
than that of the Cs(I) radioelement (for the final application). A simple way to overcome the problem of hazardous metal release could consist of mixing the ion-exchanger composite material with alginate or chitosan beads that have good affinity for divalent or trivalent metal cations. In any case, iron salts will be less hazardous than other heavy metals in terms of metal release. Based on these considerations, the low cost of these salts and the relatively good sorption performance, Prussian Blue-based composites appear to be good candidates for developing Cs-specific sorbents for the treatment of Cs(I) from nuclear effluents.

\section{Conclusion}

The immobilization of double metal hexacyanoferrate ionexchangers (potassium hexacyanoferrates substituted with Fe, $\mathrm{Ni}, \mathrm{Zn}, \mathrm{Co}$ and $\mathrm{Cu}$ ) in chitosan capsules (further reacetylated to chitin to improve chemical stability) produces highly efficient composite sorbents for Cs(I). The SEM-EDX analysis shows the homogeneous distribution of the ion-exchangers in the whole mass of the sorbent and their good accessibility and availability for cesium. In addition, at saturation of the sorbent $\operatorname{Cs}(\mathrm{I})$ completely exchanged $\mathrm{K}(\mathrm{I})$, as a confirmation of the sorption mechanism. X-ray diffraction analysis showed substantial differences in the spectra: while the $\mathrm{Zn}$ ion-exchanger was characterized by a well-defined structure (large size of crystals), the other ion-exchangers showed poorly resolved spectra due to the small size of ion-exchanger crystals, and possibly to the coexistence of different chemical compositions (different degrees of substitution, different hexacyanoferrate compounds). The TEM analysis confirmed the singularity of the $\mathrm{Zn}$ compound (large size $\approx 250 \mathrm{~nm}$, cubic crystals) against other ion-exchangers (smoothened/melted shapes with sizes below 20-30 nm, confirmed by X-ray diffraction analysis). The elemental analysis showed that the load of ion-exchanger in the composite material was close to $20 \%$, leading to high sorption capacities. However, it is noteworthy that the "dilution" of the ion-exchanger tested on the nickel-potassium hexacyanoferrate/ chitin composite in the biopolymer matrix enhances the rational use of the ion-exchanger: the maximum sorption capacity reported as a function of the ion-exchanger content increased with its dilution. Uptake kinetics are controlled by intraparticle diffusion (though the kinetic profiles were also well fitted by the pseudo-second order rate equation). The intraparticle diffusion coefficient varied in the range of 2.2-8.4 $\times 10^{-10} \mathrm{~m}^{2} \mathrm{~min}^{-1}$ for Ni-, $\mathrm{Zn}-$, Co- and Cu-composites (being slightly superior for the Fe-composite, 2.6-4.9 $\times 10^{-10} \mathrm{~m}^{2}$ $\min ^{-1}$ ), depending on the size of the beads and the ionexchanger. The comparison of maximum sorption capacities ( $m g \mathrm{Cs}^{-1}$ composite) leads to the following ranking: $\mathrm{Cu}(118)>$ $\mathrm{Ni}(101)>\mathrm{Zn}(96)>\mathrm{Co}(81)>\mathrm{Fe}(42)$. However, based on safety/ environmental considerations and economic parameters, the preference could be re-oriented to Prussian Blue and zinc-based compounds (zinc- and iron-potassium hexacyanoferrate/chitin composite). This conclusion is partly confirmed comparing the results obtained for the sorption of ${ }^{137} \mathrm{Cs}$. The materials can be ranked in terms of $K_{\mathrm{d}}\left(\mathrm{L} \mathrm{g}^{-1}\right)$ as $\mathrm{Co}(3329) \gg \mathrm{Fe}(1869) \gg \mathrm{Cu}$
(1096) $\gg \mathrm{Ni}(348)>\mathrm{Zn}$ (162). Prussian Blue incorporated into chitin capsules is thus a good candidate for competitive and environmentally friendly materials for Cs removal from radionuclide-containing effluents. Current studies are focusing on the influence of the synthesis of the ion-exchanger on the sorption properties of encapsulated materials.

\section{Acknowledgements}

Authors acknowledge J.-M. Taulemesse for technical support for SEM-EDX analysis.

\section{References}

1 P. J. Faustino, Y. Yang, J. J. Progar, C. R. Brownell, N. Sadrieh, J. C. May, E. Leutzinger, D. A. Place, E. P. Duffy, F. Houn, S. A. Loewke, V. J. Mecozzi, C. D. Ellison, M. A. Khan, A. S. Hussain and R. C. Lyon, J. Pharm. Biomed. Anal., 2008, 47, 114-125.

2 C. Loos-Neskovic, S. Ayrault, V. Badillo, B. Jimenez, E. Garnier, M. Fedoroff, D. J. Jones and B. Merinov, J. Solid State Chem., 2004, 177, 1817-1828.

3 A. G. Volkov, S. Paula and D. W. Deamer, Bioelectrochem. Bioenerg., 1997, 42, 153-160.

4 F. Han, G.-H. Zhang and P. Gu, J. Hazard. Mater., 2012, 225226, 107-113.

5 R. Harjula, J. Lehto, A. Paajanen, L. Brodkin and E. Tusa, Nucl. Sci. Eng., 2001, 137, 206-214.

6 V. Milyutin, O. Kononenko, S. Mikheev and V. Gelis, Radiochemistry, 2010, 52, 281-283.

7 S. Tsuruoka, B. Fugetsu, F. Khoerunnisa, D. Minami, K. Takeuchi, M. Fujishige, T. Hayashi, Y. A. Kim, K. C. Park, M. Asai, K. Kaneko and M. Endo, Mater. Express, 2013, 3, 21-29.

8 C. Dwivedi, A. Kumar, K. K. Singh, A. K. Juby, M. Kumar, P. K. Wattal and P. N. Bajaj, J. Appl. Polym. Sci., 2013, 129, 152-160.

9 D. Kołodyńska, Z. Hubicki and B. Kubica, Sep. Sci. Technol., 2012, 47, 1361-1368.

10 A. Nilchi, H. Atashi, A. H. Javid and R. Saberi, Appl. Radiat. Isot., 2007, 65, 482-487.

11 C.-Y. Chang, L.-K. Chau, W.-P. Hu, C.-Y. Wang and J.-H. Liao, Microporous Mesoporous Mater., 2008, 109, 505-512.

12 T. Sangvanich, V. Sukwarotwat, R. J. Wiacek, R. M. Grudzien, G. E. Fryxell, R. S. Addleman, C. Timchalk and W. Yantasee, J. Hazard. Mater., 2010, 182, 225-231.

13 C. Delchet, A. Tokarev, X. Dumail, G. Toquer, Y. Barre, Y. Guari, C. Guerin, J. Larionova and A. Grandjean, RSC Adv., 2012, 2, 5707-5716.

14 A. Tokarev, P. Agulhon, J. Long, F. Quignard, M. Robitzer, R. A. S. Ferreira, L. D. Carlos, J. Larionova, C. Guerin and Y. Guari, J. Mater. Chem., 2012, 22, 20232-20242.

15 P. Krys, F. Testa, A. Trochimczuck, C. Pin, J. M. Taulemesse, T. Vincent and E. Guibal, J. Colloid Interface Sci., 2013, 409, 141-150. 
16 H. Mimura, W. Yan, Y. Wang, Y. Niibori, I. Yamagishi, M. Ozawa, T. Ohnishi and S. Koyama, Nucl. Eng. Des., 2011, 241, 4750-4757.

17 T. Vincent, J.-M. Taulemesse, A. Dauvergne, T. Chanut, F. Testa and E. Guibal, Carbohydr. Polym., 2013, 99, 517-526.

18 A. K. Vipin, B. Hu and B. Fugetsu, J. Hazard. Mater., 2013, 258, 93-101.

19 B. Folch, J. Larionova, Y. Guari, K. Molvinger, C. Luna, C. Sangregorio, C. Innocenti, A. Caneschi and C. Guerin, Phys. Chem. Chem. Phys., 2010, 12, 12760-12770.

20 C. Vincent, A. Hertz, T. Vincent, Y. Barré and E. Guibal, Chem. Eng. J., 2014, 236, 202-211.

21 A. Kitajima, H. Tanaka, N. Minami, K. Yoshino and T. Kawamoto, Chem. Lett., 2012, 41, 1473-1474.

22 Z. Du, M. Jia and X. Wang, J. Radioanal. Nucl. Chem., 2013, 298, 167-177.

23 A. V. Voronina, V. S. Semenishchev, E. V. Nogovitsyna and N. D. Betenekov, J. Radioanal. Nucl. Chem., 2013, 298, 67-75.

24 N. L. Torad, M. Hu, M. Imura, M. Naito and Y. Yamauchi, J. Mater. Chem., 2012, 22, 18261-18267.

25 Y. Hirayama, Y. Okamura, K. Fujiwara, T. Sugo, D. Umeno and K. Saito, Kagaku Kogaku Ronbunshu, 2013, 39, 28-32.

26 T. P. Valsala, S. C. Roy, J. G. Shah, J. Gabriel, K. Raj and V. Venugopal, J. Hazard. Mater., 2009, 166, 1148-1153.

27 B. Li, J. Liao, J. Wu, D. Zhang, J. Zhao, Y. Yang, Q. Cheng, Y. Feng and N. Liu, Nucl. Sci. Tech., 2008, 19, 88-92.

28 C. Loos-Neskovic, M. Fedoroff and E. Garnier, Talanta, 1989, 36, 749-759.

29 P. Sorlier, A. Denuziere, C. Viton and A. Domard, Biomacromolecules, 2001, 2, 765-772.

30 C. Thammawong, P. Opaprakasit, P. Tangboriboonrat and P. Sreearunothai, J. Nanopart. Res., 2013, 15, 1-10.

31 J. Orechovska and P. Rajec, J. Radioanal. Nucl. Chem., 1999, 242, 387-390.

32 V. Georgieva, D. Zvezdova and L. Vlaev, J. Therm. Anal. Calorim., 2013, 111, 763-771.

33 D. M. Gil, M. Avila, E. Reguera, S. Pagola, M. Ines Gomez and R. E. Carbonio, Polyhedron, 2012, 33, 450-455.

34 C. Loos-Neskovic, M. Fedoroff, E. Garnier and P. Gravereau, Talanta, 1984, 31, 1133-1147.
35 J. Lehto, S. Haukka, R. Harjula and M. Blomberg, J. Chem. Soc., Dalton Trans., 1990, 1007-1011.

36 J. Brugnerotto, J. Lizardi, F. M. Goycoolea, W. ArguellesMonal, J. Desbrieres and M. Rinaudo, Polymer, 2001, 42, 3569-3580.

37 J. Balmaseda, E. Reguera, J. Rodriguez-Hernandez, L. Reguera and M. Autie, Microporous Mesoporous Mater., 2006, 96, 222-236.

38 N. R. de Tacconi, K. Rajeshwar and R. O. Lezna, Chem. Mater., 2003, 15, 3046-3062.

39 C. Tien, Adsorption Calculations and Modeling, ButterworthHeinemann, Newton, MA, 1994.

40 K. Shakir, M. Sohsah and M. Soliman, Sep. Purif. Technol., 2007, 54, 373-381.

41 Y. S. Ho, Water Res., 2006, 40, 119-125.

42 Ľ. Vrtoch, M. Pipíška, M. Horník, J. Augustín and J. Lesný, J. Radioanal. Nucl. Chem., 2011, 287, 853-862.

43 J. Crank, The Mathematics of Diffusion, Oxford University Press, Oxford, G.B., 1975.

44 Y. Marcus, Ion Properties, Marcel Dekker, Inc., New York, NY, 1997.

45 T. J. Tranter, T. A. Vereshchagina and V. Utgikar, Solvent Extr. Ion Exch., 2009, 27, 199-218.

46 R. Jalali-Rad, H. Ghafourian, Y. Asef, S. T. Dalir, M. H. Sahafipour and B. M. Gharanjik, J. Hazard. Mater., 2004, 116, 125-134.

47 H. Parab and M. Sudersanan, Water Res., 2010, 44, 854860.

48 L. Wang, M. Feng, C. Liu, Y. Zhao, S. Li, H. Wang, L. Yan, G. Tian and S. Li, Sep. Sci. Technol., 2009, 44, 4023-4035.

49 A. Nilchi, R. Saberi, M. Moradi, H. Azizpour and R. Zarghami, Chem. Eng. J., 2011, 172, 572-580.

50 E. Rumyantseva, A. Veleshko, S. Kulyukhin, I. Veleshko, D. Shaitura, K. Rozanov and N. Dmitrieva, Radiochemistry, 2009, 51, 496-501.

51 S. Taj, D. Muhammad, M. A. Chaudhry and M. Mazhar, J. Radioanal. Nucl. Chem., 2011, 288, 79-88.

52 V. Avramenko, S. Bratskaya, V. Zheleznov, I. Sheveleva, O. Voitenko and V. Sergienko, J. Hazard. Mater., 2011, 186, 1343-1350. 